\title{
Activity-induced Changes in Synaptic Release Sites at the Crayfish Neuromuscular Junction
}

\author{
J. M. Wojtowicz, L. Marin, and H. L. Atwood \\ MRC Group in Nerve Cells and Synapses, Department of Physiology, University of Toronto, Toronto, Ontario, Canada \\ M5S 1 A8
}

Crustacean motor axons provide a model in which activitydependent changes in synaptic physiology and synaptic structure can be concurrently observed in single identifiable neurons. In response to a train of stimulation, crustacean neuromuscular junctions undergo pronounced facilitation of transmitter release. The effects of maintained high-frequency stimulation may persist for at least several hours ("longterm facilitation"). Electrophysiological studies suggest that the number of "active" synapses contributing transmitter quanta at low frequencies of stimulation increases during and after a train of high-frequency stimulation. However, at different terminal recording sites the effect of stimulation varies, and it was observed that not all released quanta produce a voltage change in the postsynaptic muscle cell. Electron microscopic examinations of serial sections from nerve terminals subjected to stimulation were made to determine whether changes in synaptic structure could be correlated with activity-induced long-lasting enhancement of transmission. A procedure was introduced for marking a recorded terminal with fluorescent polystyrene microspheres, which are visible in electron micrographs of the recording site. Crustacean nerve terminals possess a large number of discrete synapses, a small fraction of which have multiple presynaptic "active zones" (dense bodies with clustered synaptic vesicles, thought to represent sites of evoked transmitter release). In terminals previously stimulated, the proportion of synapses with multiple "active zones" is greater than in control unstimulated terminals. Total synaptic vesicle counts and readily releasable vesicles at synapses are not significantly different in previously stimulated terminals and controls. In terminals fixed during stimulation, a few synapses show evidence of division in "active zones," and synaptic vesicle counts are lower than in controls. The observations lead to the hypothesis that activity-dependent enhancement of synaptic transmission in these neurons is associated with an increase in synapses with multiple "active zones," but not with long-lasting changes in releasable

\footnotetext{
Received July 20, 1993; revised Nov. 12, 1993; accepted Nov. 30, 1993.

We thank Ms. M. Hegström-Wojtowicz for technical assistance, and Dr. B. Smith (University of Victoria, Canada) for advice on statistical quantal analysis. This work was supported by research grants from the Medical Research Council of Canada (J.M.W., H.L.A.) and Natural Sciences and Engineering Research Council of Canada (H.L.A.). Three-dimensional reconstruction software from the Laboratory for Iligh Voltagc Electron Microscopy at the University of Colorado was used for measuring and reconstructing terminals and synapses.

Correspondence should be addressed to Dr. H. L. Atwood, Department of Physiology, Medical Sciences Building, University of Toronto, Toronto, Ontario, Canada M5S 1 A8.

Copyright (C) 1994 Society for Neuroscience $0270-6474 / 94 / 143688-16 \$ 05.00 / 0$
}

synaptic vesicles. It is postulated that synapses endowed with multiple "active zones" are responsible for most of the transmitter release at low frequencies of stimulation, while synapses with fewer "active zones" are recruited at higher frequencies of stimulation. Adaptive transformation of synaptic physiology and structure can occur in a relatively short time, but involves relatively few of the synapses available on a nerve terminal.

[Key words: crustacean, long-term facilitation, neuromuscular junction, synapse structure, quantal release, "missing" quanta]

Alterations of activity in nerve cells often lead to long-term and short-term changes in physiological properties of their synapses. Such changes have been well studied in several different neural systems, including various parts of the mammalian CNS (McNaughton, 1993) and identifiable neurons or groups of neurons in the mollusk Aplysia (Byrne et al., 1993). Long-term synaptic changes are postulated to be involved in some forms of learning, pathway enhancement, and memory in the CNSs of several species (Bailey and Kandel, 1993); research on this hypothesis continues actively.

The idea that structural changes are linked to altered synaptic efficacy has been presented many times for a variety of neural systems (Greenough, 1984; Bailey and Kandel, 1993; Lisman and Harris, 1993). For example, changes in numbers of synapses following conditioning (Artyukhina and Ryabinina, 1978; Wenzel et al., 1980) or in learning situations (Greenough et al., 1985; Black et al., 1990) have been reported in the mammalian brain. Perforated synapses (Jones and Calverley, 1991) have been correlated with functional changes linked to memory (Greenough et al., 1978; Geinisman et al., 1986) and kindling (Geinisman et al., 1989, 1992; Gomez et al., 1990). Changes in synaptic curvature have also been linked to functional alterations (Petit ct al., 1989; Tsicn, 1989). In the rat hippocampus, several structural changes have been reported in association with long-term potentiation (Lee et al., 1979; Petukhov and Popov, 1986; Schuster et al., 1990). Counterbalancing these reports are a few contrary ones in which no synaptic ultrastructural changes were seen following long-term activation of specific neural pathways (Hawdon et al., 1988).

Allempts to correlate structural and functional changes at the synaptic level in the mammalian brain have thus generated many suggestive observations that lend support to the general hypothesis that structural changes are important for synaptic performance. However, most of these studies do not attempt to correlate the structural and functional changes in the same neuron. Rather, they rely on statistical comparisons of large samples 
of neurons, which would include neurons with many different histories of activity and function. This lowers the precision of the attempted correlations, and makes it difficult to say whether neuronal activity per se is responsible for structural changes in an individual neuron. Complex trophic effects, generalized interactions with glial cells, or actions of released diffusible agents such as nitric oxide (Haley et al., 1992) or carbon monoxide (Verma et al., 1993) could be involved, and could affect inactive members of neuronal populations sampled for ultrastructural changes. The extent and probability of such effects have yet to be fully assessed.

In systems involving fewer identifiable neurons, it is possible to ascertain or control the activity of individual neurons, and to undertake ultrastructural studies on a neuron for which the activity level is accurately known. Changes induced by neuronal activity per se can be studied, as well as changes induced by neuromodulators and neurotransmitters. This approach has been taken in molluscan neurons, in which structural changes have becn linked to the establishment of long-term habituation and sensitization (Bailey and Chen, 1983; Abrams and Kandel, 1988), to the actions of neurotransmitters and neuromodulators, including 5-HT and FMRFamide (Bailey et al., 1992), and to elevation of intracellular cAMP concentration (Nazif et al., 1991). There is also evidence for synaptic modification in identified crustacean motor neurons as a result of alterations in neuronal activity (Chiang and Govind, 1986; Wojtowic\% et al., 1989a). Thus, large identifiable invertebrate neurons offer appropriate models for study of the effects of activity or neuromodulators on synaptic physiology and structure under controlled conditions in a single identifiable neuron.

Crustacean neuromuscular synapses exhibit both short-term and long-term alterations in functional state (Atwood and Wojtowicz, 1986; Zucker, 1989; Zucker et al., 1991). One of the long-term changes, termed "long-term facilitation" (Sherman and $\Lambda$ twood, 1971), is induced by prolonged stimulation at moderate frequencies, and leads to enhancement of transmission that persists for several hours (Atwood et al., 1975) or as long as 1-2 d (Lnenicka and Atwood, 1985). This synaptic change is thought to depend upon changes induced through presynaptic actions of CAMP-dependent protein kinase (Atwood et al., 1989; Dixon and Atwood, 1989), but the nature of the synaptic modifications has yet to be fully described. Available evidence suggests that in this type of neuron, the changes are entirely presynaptic, and that "silent" synapses on the motor nerve terminal shift to an "active" mode following tetanic stimulation (Atwood and Wojtowicz, 1986; Wojtowicz and Atwood, 1986). There is also preliminary ultrastructural evidence suggesting that more presynaptic "active zones" become visible once the long-term synaptic changes have been induced (Wojtowicz et al., 1989a).

The present study was undertaken to test further the hypothesis that structural changes in synapses of crustacean motoneurons are associated with changes in neuronal activity. The neuron chosen for these experiments is the motor neuron of the "opener" muscle of the crayfish walking leg, since long-term facilitation can be reliably induced in this neuron, and the general ultrastructure of the synapses is well known from previous investigations (Jahromi and Atwood, 1974; Florey and Cahill, 1982).

The results confirm that physiological and structural changes in synapses can be induced in a relatively short time by increased neuronal activity. These activity-driven changes affect a rela- tively small proportion of the total synapse population. In addition, evidence relating to the structural features of active and less active synapses is provided.

\section{Materials and Methods}

The "opener" muscle in walking legs of small crayfish was prepared for physiological recording as in previous studies (Wojtowicz and Atwood, 1984, 1985). The preparations were maintained during experiments in modified Van Harreveld's solution (Wojtowicz and Atwood, 1984) at a temperature of $15^{\circ} \mathrm{C}$. Standard methods of stimulation, intracellular recording, and "macropatch" recording from individual nerve terminal "boutons" containing active synapses were employed (Atwood et al., 1987).

Quantal currents recorded by a "macropatch" electrode placed over active synapses could readily be resolved to determine the number of quanta released per impulse (quantal content) at frequencies of stimulation below $10 \mathrm{~Hz}$. In addition, estimates of the number of "active" synapses in a recording site were made using a statistical procedure based upon a modified binomial model with unequal probabilities of response allowed for contributing response elements (Wojtowicz et al. 1991). The method for finding the best estimates of parameters $n$ and $p$ is essentially the same as that previously described (Wojtowicz et al., 1991). In brief, the observed counts of released quanta were fitted to either binomial, Poisson, or nonuniform binomial models. For each model, we minimized the $\chi^{2}$ statistic, using a computerized, iterative procedure. The modified Akaike information criterion (AIC) was used to select a model (Smith et al., 1991). This criterion is a $\chi^{2}$ criterion with a "penalty" term related to the number of estimated parameters. For all data sets included in this article the binomial nonuniform model was superior. However, in many cases the difference between a simple binomial and a nonuniform model was small, suggesting similar probabilities among the release sites.

In cases for which data sets were described by a binomial model, we were able to use a "bootstrap" sampling procedure to estimate standard errors of the parameter $\bar{p}$ estimates. The procedure consists of choosing 500 random samples, with replacement, from the original data set containing, for example, 1368 failures of transmission, 157 one-quantum events, and seven two-quantum events. For each sample, the estimates of $n$ and $\bar{p}$ were obtained within a specified range of possible $n$ values (arbitrarily chosen to be 1-20). A collection of 500 bootstrap estimates was used to estimate standard errors of the estimated parameter $\bar{p}$ (see Table 1). We also report the median (most commonly occurring) values of $n$ in the selected range.

Intracellularly recorded excitatory postsynaptic potentials (EPSPs) could also be analyzed to provide estimates of the number of "active" synapses (Smith et al., 1991), since the muscle fibers in small crayfish are practically isopotential (Bittner, 1968; Wojtowicz and Atwood, 1986). The procedures as outlined were applied to data sets collected at several frequencies of stimulation, and to data collected from individual muscle fibers at a low frequency of stimulation before and after induction of long-term facilitation (LTF).

A procedure was developed to mark recording sites for later identification in electron micrographs. The "macropatch" recording electrode was filled with the modified van Harreveld's solution containing a low density of fluorescent polystyrene microspheres $(0.5 \mu \mathrm{m}$ diameter; Duke Scientific Co.). When the electrode was applied to a recording site to collect quantal currents (Fig. 1), some of the fluorescent beads adhered to the surface of the muscle fiber at the recording site, and could be seen in the electron microscope in thin sections made at this site (Fig. 2). The fluorescent beads could be visualized on the specimen under a fluorescence microscope after the specimen had been embedded in resin; this permitted more rapid and accurate localization of the recording site for electron microscopy. However, some specimens were damaged, and in others the beads were lost during the procedure. In the present work, one specimen from which good recordings had been obtained was successfully preserved, serially sectioned, and reconstructed with this method.

Electron microscopy of nerve terminals from "control," "stimulated," and "long-term facilitated" specimens was conducted using well estab lished procedures (Jahromi and Atwood, 1974; Govind et al., 1982). "Control" specimens were dissected and fixed after being held in physiological solution for the same length of time as the "long-term facilitated" specimens. "Short-term stimulated" specimens were from preparations in which fixation blocked nerve-evoked release $30 \mathrm{sec}$ to $1 \mathrm{~min}$ 


\section{B. Reconstructed terminal}

\section{A. Experimental arrangement}

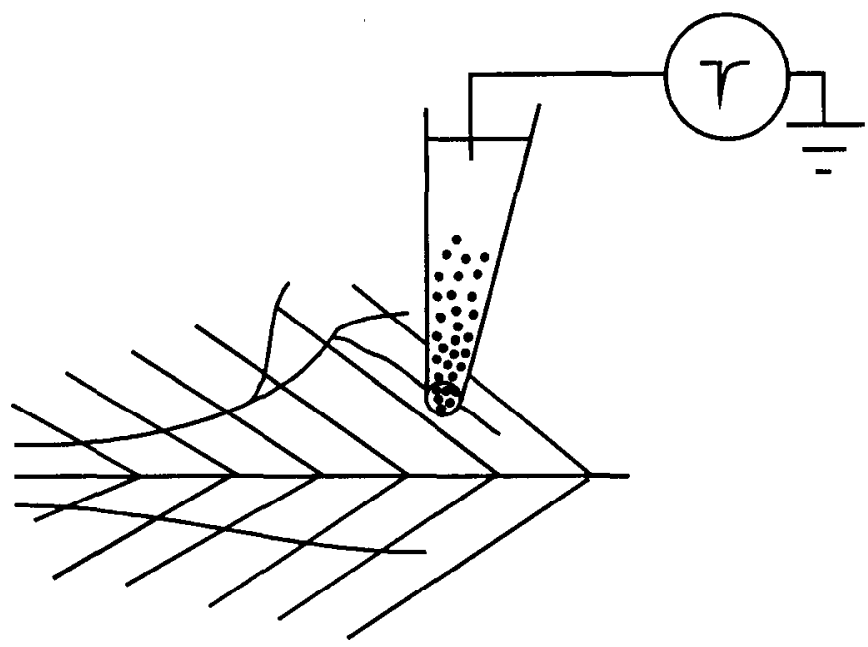

C.

Macropatch recording

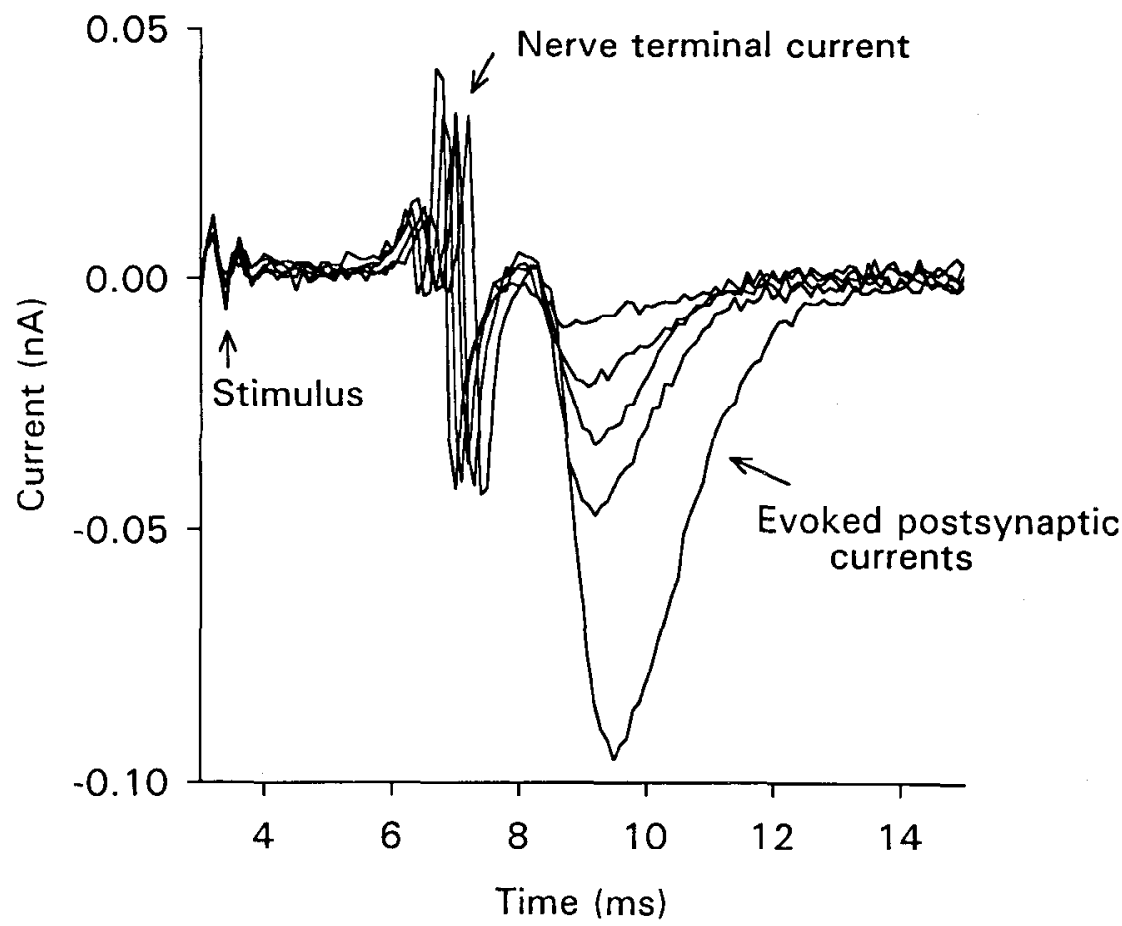

3D Reconstruction

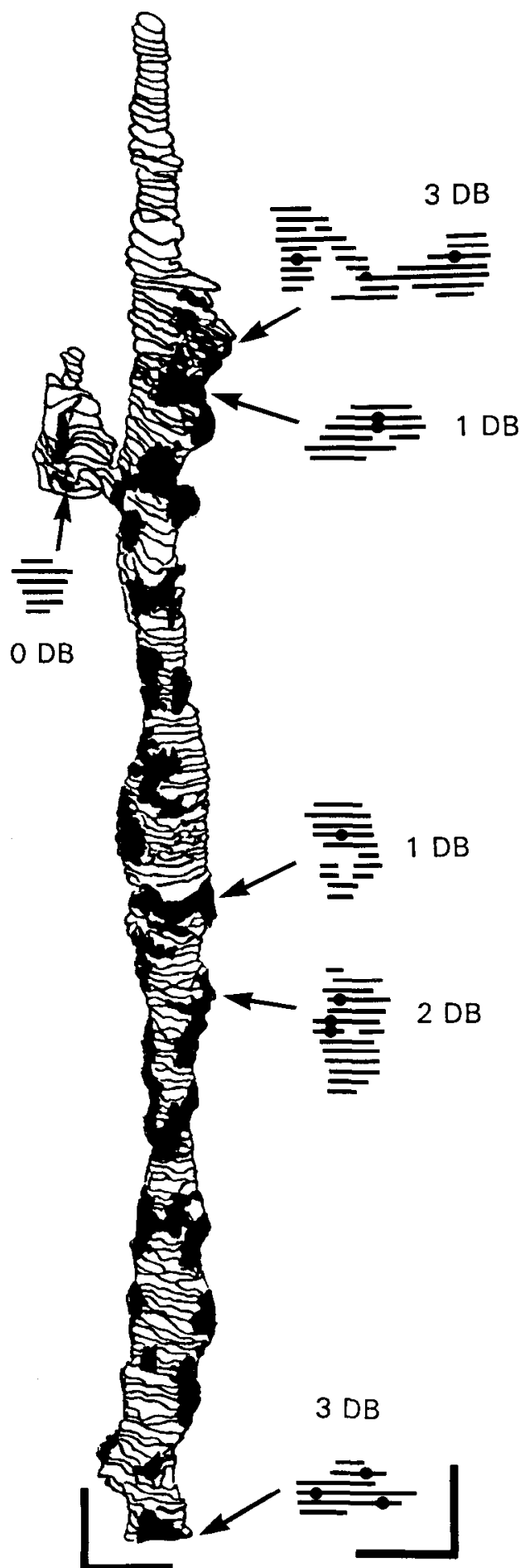

Figure 1. Correlation of electrophysiological and ultrastructural results at a single recording site. $A$, Experimental arrangement for recording and labeling with a macropatch electrode. The electrode is filled with standard crayfish solution containing fluorescent polystyrene beads, some of which are deposited upon the surface of the muscle fiber at the recording site. $B$, Reconstruction of the labeled terminal, with face views of representative synapses. Synapses are shown as black areas in the reconstruction. Individual representative synapses illustrate cases in which zero, one, two, and three presynaptic dense bodies $(D B)$ were observed; these are shown in location on the face view of each synapse. Altogether, 43 synapses were found within the lumen of the electrode. Scale bars, $1 \mu \mathrm{m}$. C. Evoked synaptic currents at frequencies of $2,3,4,5$, and $10 \mathrm{~Hz}$ at the labeled recording site in the central region of the crayfish opener muscle. Averages of 200 sweeps are shown for each frequency. Transmitter release increases progressively with frequency of stimulation. 

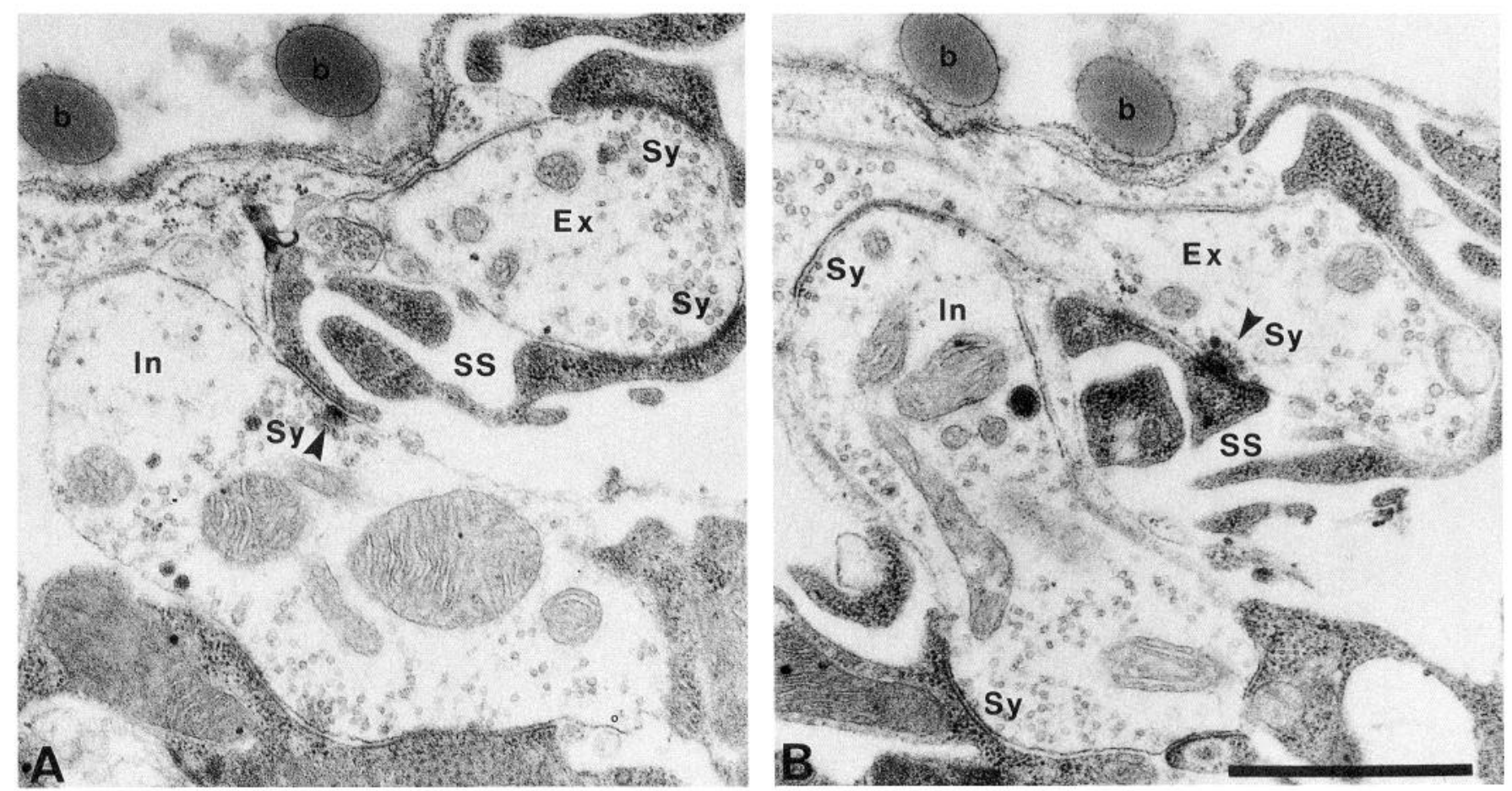

Figure 2. Electron micrographs of bead deposition over synapses, to illustrate the procedure for labeling an active recording site. Preservation of the nerve terminals and subsynaptic apparatus is impaired by the recording and labeling procedures, but synapses and their associated presynaptic dense bodies are preserved. Ex, excitatory nerve ending; $I n$, inhibitory nerve ending; $S S$, subsynaptic apparatus; $b, 0.5 \mu \mathrm{m}$ polystyrene bead; arrowheads, presynaptic dense bodies; Sy, synapses. Scale bar, $1 \mu \mathrm{m}$.

after the beginning of $20 \mathrm{~Hz}$ stimulation of the excitatory axon. (LTF is not induced by this period of stimulation.) "Long-term stimulated" specimens were from a preparation fixed after $10 \mathrm{~min}$ of $20 \mathrm{~Hz}$ stimulation, which is sufficient to induce LTF. "Long-term facilitated" specimens were fixed $45 \mathrm{~min}$ after the end of a $20 \mathrm{~Hz}$ tetanus lasting 10 min; at this time, amplitudes of EPSPs measured at $1-5 \mathrm{~Hz}$ were generally $50-100 \%$ larger than before the inducing stimulation. In the present study, four "control," two "short-term stimulated" $(20 \mathrm{~Hz}, 1 \mathrm{~min})$, one "long-term stimulated" $(20 \mathrm{~Hz}, 10 \mathrm{~min})$, and four "long-term facilitated" specimens were examined in detail. In each specimen, serial sections were cut from several nerve endings to provide a large number of complete synapses.

Measurements of synaptic and nerve terminal surface areas were made from micrographs using a digitizing tablet (Digi-Pad 5, GTCO Corporation) from which the information for each section could be read into a computer. Individual synapses were defined on morphological grounds as regions of densely staining pre- and postsynaptic membranes with uniform separation of $20 \mathrm{~nm}$ (see Jahromi and Atwood, 1974; Wojtowicz et al., 1989a). An active site (or zone) within the synapse is characterized as a dense bar or projection associated with the presynaptic membrane and closely associated with a cluster of synaptic vesicles (Jahromi and Atwood, 1974). The information from all sections was combined for each terminal to provide values of surface area for each synapse, and total surface area of the terminal. Presynaptic "dense bodies" (putative "active zones") were counted for each synapse. For some specimens, synaptic vesicles in the terminal were counted, and "readily releasable" vesicles (those within $0.05 \mu \mathrm{m}$ of a synapse) were counted separately. These data were tabulated to permit comparisons of the synapses from the four experimental conditions.

\section{Results}

\section{Labeling an active recording site}

For an assessment of the number and type of synapses present at a site where quantal currents could be recorded with "macropatch" electrode, the "bead labeling" method described in Materials and Methods was employed (Figs. 1, 2). For this to be successful, several criteria had to be met. (1) The electrical recordings had to be of good quality, with large numbers of responses collected for statistical analysis (Wojtowicz et al., 1991). (2) The recordings had to meet criteria of stationarity over the period of the experiment (Smith et al., 1991). (3) Fluorescent beads applied through the electrode had to be visible on the specimen after it was prepared for electron microscopy, so that the recording site could be unambiguously located. (4) The beads had to be visible in electron micrographs. (5) The preservation of the specimen had to be good enough to locate intact synapses and presynaptic "dense bodies." (6) A complete serial sectioning of the entire recording site, as delimited by the marker beads, had to be completed with minimal loss of sections.

After several attempts, in which one or more of the above criteria were not met, a good site was located that met the criteria and for which a reasonably good series of sections, $86 \%$ complete, was obtained. Altogether, 260 sections, representing 19.5 $\mu \mathrm{m}$ of the nerve ending within the lumen of the electrode, were analyzed. The polystyrene microspheres were clearly visible in electron micrographs (Fig. 2); they occurred at higher density near the edges of the recording site than in its center. The length of the reconstructed terminal matched the known diameter of the recording electrode $(20 \mu \mathrm{m})$. The preservation of the nerve terminals and associated subsynaptic apparatus was not as good as in material not subjected to the long recording procedure (compare Figs. 2, 7): in the recorded specimen, the membranes of nerve terminals were sometimes not clearly defined, and the subsynaptic apparatus appeared shrunken. Nevertheless, synapses and their associated presynaptic dense bodies with synaptic vesicle clusters appeared intact, and could be counted and analyzed. Due to loss of sections at a few locations, some synapses were incompletely sampled. However, in many cases the number of sections lost for individual synapses was small, and 
A
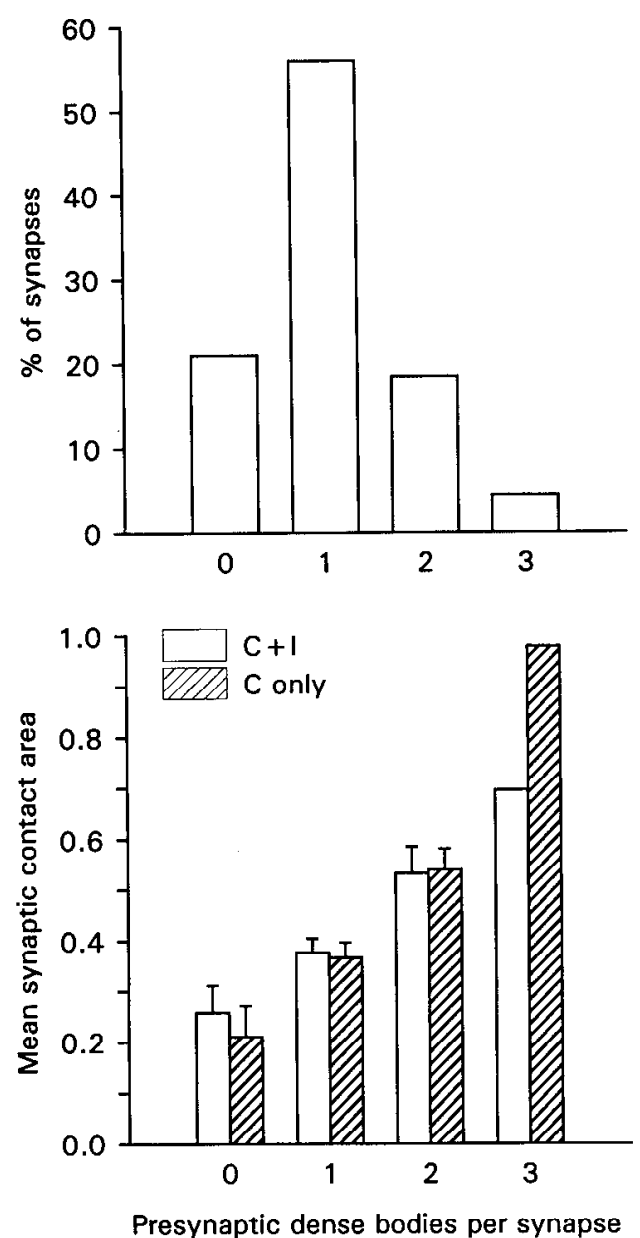

Figure 3. Histograms of presynaptic dense body distribution among synapses of the labeled terminal $(A)$ and distribution of individual contact areas among synapses with different numbers of presynaptic dense bodies $(B)$. Error bars show SEM, and are not included for the synapses with three presynaptic dense bodies due to the small sample size. The overall results for complete synapses only $(C$ only), and for complete and incomplete synapses $(C+I)$, are not significantly diffcrent. Synaptic area increases with the number of presynaptic dense bodies.

the error in synaptic area was minimal or easily corrected. For the sample as a whole, mean values of synaptic areas based upon data for complete synapses taken by themselves were similar to the mean values based upon combined data for complete and incomplete synapses (Fig. $3 B$ ). Furthermore, the counts of dense bodies per synapse obtained in this sample (Fig. $3 A$ ) were similar to those obtained in larger samples from terminals not exposed to recording and labeling (see Fig. 7); this indicates that most essential features of the synapses were preserved in the labeling procedure.

The reconstructed terminal had 43 synapses distributed along its length (Fig. $1 B$ ). Of these, the majority (56\%) had a single presynaptic dense body; $21 \%$ had no dense body; and the remainder had two or three (Fig. $3 A$ ). Synaplic contact area increased with the number of presynaptic dense bodies present (Fig. $3 B$ ). Some synapses, particularly the larger ones, were perforated or indented (Fig. $1 B$ ). The results are generally similar to those of previous serial sectioning studies of the crayfish opener muscle (Jahromi and Atwood, 1974; Atwood and Kwan, 1976; Wojtowicz et al., 1989a).
Currents from this active recording site were collected at several different frequencies and analyzed as described in Materials and Methods (Table 1). Quantal content increased, as expected, with frequency; this change was brought about by increases in both the statistically observed number of responding units and the average probability of response in the nonuniform binomial model. The number of responding units $(n)$ appeared to increase when the frequency of stimulation was raised. In addition, the estimated average probability of response increased with frequency above $5 \mathrm{~Hz}$ (see also Fig. 4). A similar pattern of results has been reported previously (Hatt and Smith, 1976).

The results of the binomial analysis suggest that only a few of the 43 separate synapses at the recording site are active at low frequencies, but that the number of active synapses increases with frequency. Further consideration of the relationship between physiological and morphological findings will be left to the Discussion.

\section{Physiological manifestations of long-term facilitation}

During sustained tetanic stimulation, the EPSP usually grows progressively in amplitude (Sherman and Atwood, 1971). Upon cessation of the stimulation, the EPSP evoked by brief tests at a low-frequency decays after several minutes to a maintained amplitude that is frequently about twice the amplitude observed before the tetanic stimulation. Previous studies have indicated that both the intracellularly recorded EPSP (Wojtowicz and Atwood, 1986) and the extracellularly recorded synaptic current (Wojtowicz et al., 1988) are larger mainly because additional "responding units" contribute to the response.

In the present work, previous observations were extended through analyses of intracellularly recorded EPSPs and synaptic currents recorded simultaneously with macropatch electrodes at active sites. Records were made at times corresponding to fixation of specimens for electron microscopy. Examples of the records and analyses appear in Figures 4-6.

The results generally confirmed previous work (Wojtowicz et al., 1991), but additional new observations were added. It was found that not all active recording sites studied with "macropatch" electrodes undergo long-lasting changes in release properties following induction of LTF. Also, not all quanta are effectively transmitted from the active site to the muscle fiber. Thus, results at an active recording site may, in many cases, differ from those for the muscle fiber as a whole. This is contrary to what has often been assumed in previous studies.

A representative example of simultaneously recorded EPSPs and synaptic currents is shown in Figures 4 and 5. In Figure 4, the EPSPs evoked at $5 \mathrm{~Hz}$ stimulation of the excitatory axon $(A 1)$ increased by $35 \%$ following induction of $\operatorname{LTF}(A 4)$. During $20 \mathrm{~Hz}$ tetanic stimulation delivered to induce LTF, the EPSP increased about 20 -fold $(A 2, A 3)$. The intracellularly recorded EPSP represents the combined contribution of many synaptic release sites on nerve endings acting effectively on the muscle fiber.

A more accurately defined sample of quantal release was simultaneously obtained by placing a macropatch pipette over an active recording site on the same muscle fiber. Sample records of quantal currents are shown in Figure $4 B$. Statistical analysis of the release under the patch suggests the presence of six contributing units (active synapses) with mean probability of release about 0.043 in the initial "control" record, and eight active synapses with mean probability of release of 0.044 following induction of LTF. Consistently, the analysis of such experiments 


\begin{tabular}{|c|c|c|c|c|c|}
\hline $\begin{array}{l}\text { Stim- } \\
\text { ulation } \\
(\mathrm{Hz})\end{array}$ & $\begin{array}{l}\text { Quantal } \\
\text { content }\end{array}$ & Observations & Best fit & $\begin{array}{l}\text { Parameters } \\
\bar{p} \pm \mathrm{SE} ; n\end{array}$ & $\begin{array}{l}\chi^{2} \\
\text { test }\end{array}$ \\
\hline 2 & 0.051 & $\begin{array}{c}1090 \text { zeros } \\
59 \text { ones }\end{array}$ & - & $\begin{array}{l}\bar{p}=0.05 \pm 0.006 \\
n-1(1)\end{array}$ & - \\
\hline 3 & 0.125 & $\begin{array}{r}1204 \text { zeros } \\
157 \text { ones } \\
7 \text { twos }\end{array}$ & $\begin{array}{r}1204 \\
157 \\
7\end{array}$ & $\begin{array}{l}\bar{p}=0.04 \pm 0.02 \\
n=3(3)\end{array}$ & $\begin{array}{l}\chi^{2}=0 \\
p>0.99\end{array}$ \\
\hline 4 & 0.150 & $\begin{array}{c}1213 \text { zeros } \\
196 \text { ones } \\
9 \text { twos }\end{array}$ & $\begin{array}{r}1212 \\
198 \\
8\end{array}$ & $\begin{array}{l}\bar{p}=0.075 \pm 0.019 \\
n=2(2)\end{array}$ & $\begin{array}{l}\chi^{2}=0.069 \\
p>0.97\end{array}$ \\
\hline 5 & 0.22 & $\begin{array}{c}1386 \text { zeros } \\
323 \text { ones } \\
28 \text { twos } \\
3 \text { threes }\end{array}$ & $\begin{array}{r}1385 \\
322 \\
31 \\
2\end{array}$ & $\begin{array}{l}\bar{p}-0.03 \pm 0.022 \\
n=7(7)\end{array}$ & $\begin{array}{l}\chi^{2}-0.35 \\
p>0.94\end{array}$ \\
\hline 10 & 0.56 & $\begin{array}{l}278 \text { zeros } \\
171 \text { ones } \\
43 \text { twos } \\
7 \text { threes }\end{array}$ & $\begin{array}{r}278 \\
171 \\
44 \\
7\end{array}$ & $\begin{array}{l}\tilde{p}=0.09 \pm 0.046 \\
n=6(5)\end{array}$ & $\begin{array}{l}\chi^{2}=0.01 \\
\mathrm{p}>0.99\end{array}$ \\
\hline 20 & 1.33 & $\begin{array}{c}90 \text { zeros } \\
211 \text { ones } \\
151 \text { twos } \\
40 \text { threes } \\
8 \text { fours }\end{array}$ & $\begin{array}{r}90 \\
211 \\
149 \\
42 \\
7\end{array}$ & $\begin{array}{l}\bar{p}=0.13^{a} \\
n=10\end{array}$ & $\begin{array}{l}\chi^{2}=0.13 \\
p>0.99\end{array}$ \\
\hline
\end{tabular}

Individual quantal currents, for which the averages are shown in Figure $1 C$, were counted and the observed values are listed under Observations. At $1 \mathrm{~Hz}$ there was no release in 1090 cases and one quantal current observed per stimulus in 59 cases. The fitted values (Best fit column) were obtained by matching the observed values to predicted distributions according to a nonuniform, binomial model (see Materials and Methods). In the Parameters column, $\bar{p}$ indicates the average, estimated probability of transmitter release, and $n$ is an estimate of the number of responding units (putative active release sites). Standard errors (SE) of the estimates of parameter $\bar{p}$ were obtained by bootstrap sampling (see Materials and Methods). In addition, in parentheses, we report median values of the estimates of parameter $n$ in 500 bootstrap samples. Adequacy of sample size was confirmed by dividing each data set into two subsets and comparing the estimates in each subset with that of the whole set. For the data sets presented for $3,4,5$, and $10 \mathrm{~Hz}$, the subset estimates of $n$ were consistent with $n$ estimated for the whole sample $( \pm 1) . \chi^{2}$ values for each data set (last column) indicate that in all cases, the data fit a binomial model adequately.

"In the data for $20 \mathrm{~Hz}$, it was found that there were nonuniformitics in the data that invalidated the use of the bootstrap method; thus, standard errors of $\bar{p}$ are not reported for these data. Nevertheless, a linear regression analysis indicates the tendency of the average probability $(\bar{p})$ to increase with increasing frequency of stimulation $(\mathrm{r}=0.892, \mathrm{SE}=0.018$, $\mathrm{p}=0.017)$.

indicates recruitment of additional responding units hypothesized to be active synanses, and rather small changes in mean probability of release. This is unlike the case for short-term facilitation, in which both $n$ and $\tilde{p}$ typically increase, as seen during tetanic stimulation in Figure $4 B$.

An interesting feature of this set of data is that there is little change in EPSP amplitude from $1 \mathrm{~min}$ to $10 \mathrm{~min}$ of stimulation at $20 \mathrm{~Hz}$, and the quantal content at the extracellular recording site is less at $10 \mathrm{~min}$ than at $1 \mathrm{~min}$. This implies a process of depression operating during the stimulation period. Usually, depression is not seen at these synapses during $20 \mathrm{~Hz}$ stimulation for 10 min (Wojtowicz and Atwood, 1988).

Additional quantal analyses of intracellularly recorded EPSPS also suggest recruitment of active units after $20 \mathrm{~Hz}$ stimulation, as indicated by the increase of the binomial parameter $n$ (Fig. 5). However, the $n$ values obtained with the two techniques (intracellular and extracellular) were not the same. Surprisingly, the $n$ for intracellular records was lower than under the macropatch electrode even though the latter ought to represent only a fraction of the total release occurring along the nerve terminal. In addition, values for $\bar{p}$ are generally higher for the intracellular records.
While the results are in general fully consistent with previous studies involving quantal analysis in this preparation (Wojtowicz and Atwood, 1986), the discrepancy between the results obtained by the two techniques in the same muscle fiber needs to be addressed. In about half of 12 preparations examined simultaneously with macropatch and intracellular techniques, only a small fraction of quantal currents was effectively transmitted to the postsynaptic muscle fiber. A substantial number of quantal units appear to be "missing" from the intraccllular records. This was shown not only in the results obtained from quantal analysis, but also by direct comparison of individual quanta with corresponding intracellular records.

A striking example of such a preparation is illustrated in Figure 6. In a paradigm similar to that used in Figure 4, about $30 \% \mathrm{LTF}$ was induced at a macropatch recording site by $5 \mathrm{~min}$ of $20 \mathrm{~Hz}$ stimulation, but only a marginal effect (about 6\%) on the amplitude of the EPSP was observed.

This discrepancy can he understood in the light of careful comparison of simultaneous macropatch and intracellular recordings on a one-to-one basis. Samples of quantal events and corresponding EPSPs were examined at two recording sites on the muscle fiber. In a sample of 500 trials, 13 quanta were 
$5 \mathrm{~Hz}$ control
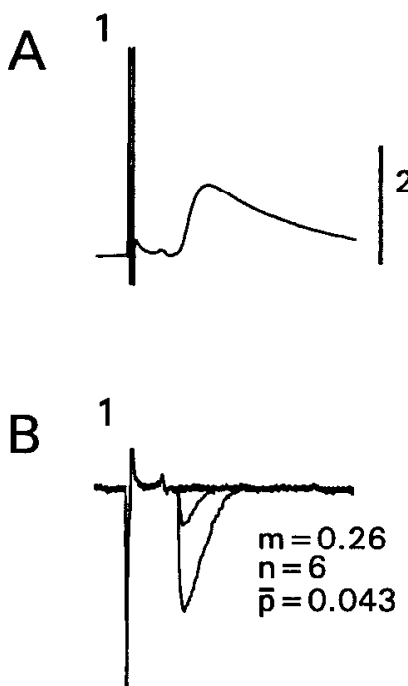

$1 \min , 20 \mathrm{~Hz}$

2
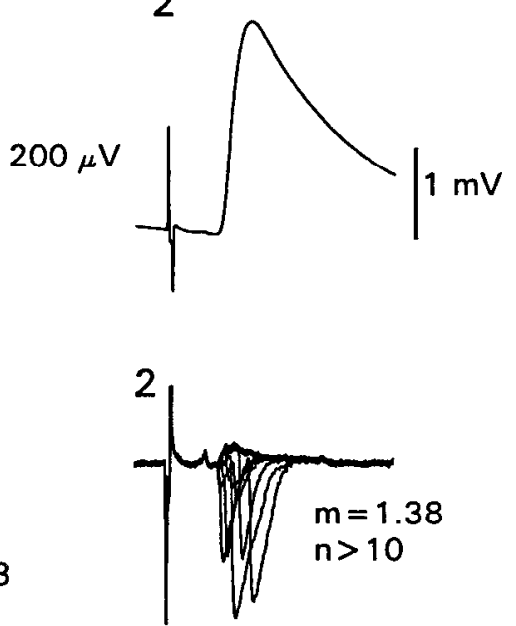

$10 \mathrm{~min}, 20 \mathrm{~Hz}$

$40 \mathrm{~min}, 5 \mathrm{~Hz}$ LTF

Figure 4. Electrophysiology of long-term facilitation $(L T F)$ : representative example of simultaneous intracellular recordings from a small muscle fiber $(A)$ and from an active site on its surface $(B)$. $A$, Averaged EPSPs before, during, and after induction of LTF. Samples correspond to the times at which specimens were fixed for electron microscopy. EPSPs during $20 \mathrm{~Hz}$ stimulation were enhanced about 20 -fold over prestimulation controls. Following tetanic stimulation (4), the EPSP at $5 \mathrm{~Hz}$ is 35\% larger than the control EPSP (shown as a dotted line for comparison). B, Macropatch recordings at a nerve terminal on the same muscle fiber. Each record shows 10 consecutive, superimposed traces of evoked quantal currents corresponding in time to EPSPs in $A$. Mean quantal content, $m$, number of participating units, $n$, and mean probability of release, $\bar{p}$, were estimated from several hundred responses. Increase in $n$ from 6 to 8 after tetanic stimulation suggests that increased transmitter release is attributable to recruitment of two active synapses. Mean probability of release remains the same after induction of LTF. During high-frequency stimulation, increases in both $n$ and $\bar{p}$ occur as quantal content increases. The nonspecific positive (upward) current recorded during the $20 \mathrm{~Hz}$ stimulation most likely originated from release sites located outside the rim of the macropatch electrode.

recorded during the control period at the first site (site 1), 10 of which did not coincide with synchronous EPSPs (Fig. 6A, Site \#1). The impotence of postsynaptic transmission was well seen when all intracellular records occurring simultaneously with the evoked quantal currents, 13 in this sample, were averaged. The result was very similar to the overall averaged response obtained from the entire 500 stimuli, for most of which release at this site did not occur (Fig. 6B, Site \#1). A similar low transmittance
Figure 5. Analysis of quantal fluctuation of the EPSPs recorded intracellularly in Figure 4. Analyses were made before $\left(A_{1}, B_{1}\right)$ and after $\left(A_{2}, B_{2}\right)$ induction of LTF. $A$, Amplitudes of about 850 individual EPSPs evoked by $5 \mathrm{~Hz}$ stimulation were measured and plotted sequentially. Despite individual fluctuations, the mean response was generally stationary during the period of stimulation. The mean response (indicated by a dotted line) and the fluctuations were increased over control $\left(A_{l}\right)$ after induction of LTF $\left(A_{2}\right)$. $B$, Amplitude-distribution histograms are superimposed on the curves representing the best fit of the data to a binomial model of transmitter release, allowing for nonequal probabilities among the release sites. The mean values of probability of release, $\bar{p}$, the number of contributing units, $n$, the mean quantal content, $m$, and mean quantal size, $\bar{q}$, are indicated. The increase in mean response amplitude and quantal content after induction of LTF can be entirely accountcd for by an increase in the binomial parameter $n$, while mean values for $\bar{p}$ and $\bar{q}$ do not change.
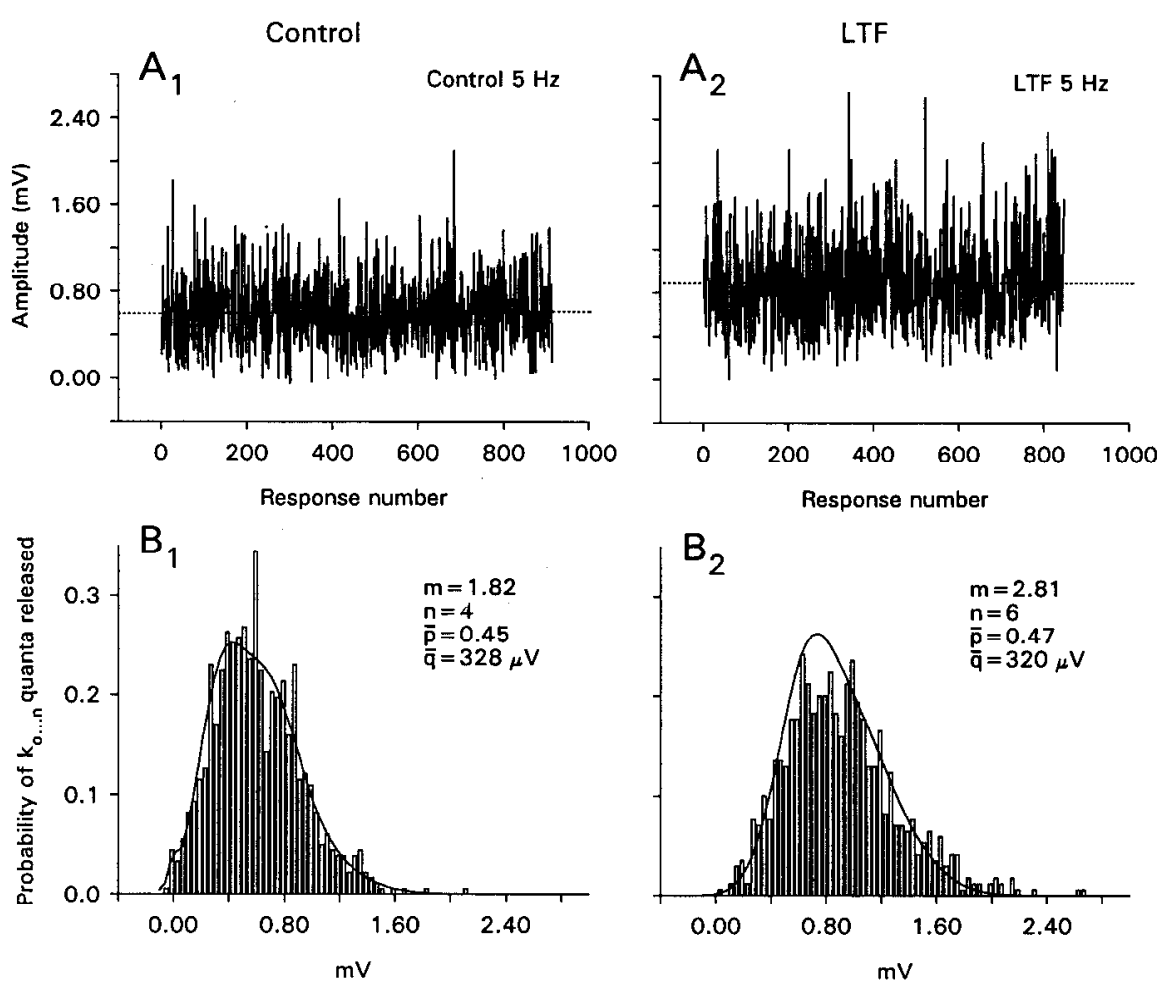
was seen after induction of LTF (Fig. $6 \mathrm{C}$, Site \#1). Thus, it is evident that LTF can occur at a subset of release sites and yet not be visible with the intracellular microelectrode.

After the recording had been completed at site 1 , another active site was located on the same muscle fiber (site 2). Here, in contrast, quantal currents were accurately transmitted to the interior of the muscle fiber (Fig. 6A, \#Site 2 ). This is seen by inspection of individual traces in Figure $6 \mathrm{~A}$, Site $\# 2$, and also in averaged records in $B$, Site $\# 2$, and $C$, Site \#2. The averaged, synchronous EPSP was about double the amplitude of the overall evoked response.

Tetanization of the preparation while recording at site 2 produced no long-lasting increase in release of transmitter at this location, but induced about $20 \%$ LTF of the intracellularly recorded EPSP. The two macropatch recording sites were within $50 \mu \mathrm{m}$ of each other and about equally distant from the intracellular microelectrode, so the failures of transmission at site 1 could not be caused by spatial decrement of potential along the muscle fiber. Moreover, previous work has shown that these small muscle fibers are almost isopotential (Bittner, 1968; Wojtowicz and Atwood, 1986). In several other experiments, even a single recording site could show some quantal currents that were transmitted, and others that were not.

The results of these experiments confirm the hypothesis that not all synapses on a neuron are modified during the LTF paradigm, and that individual active sites may behave differently during and after stimulation. Surprisingly, many synapses that release transmitter quanta do not contribute significantly to the intracellular EPSP records. From these results, it is clear that if LTF has a structural basis, relatively few synapses would be expected to undergo semipermanent modification as a result of induction of LTF.

\section{Ultrastructural correlates of LTF and tetanic stimulation}

Analyses of serial electron micrographs taken from "control," "long-term facilitated" (LTF), "short-term stimulated" $(20 \mathrm{~Hz}$, $1 \mathrm{~min})$, and "long-term stimulated" $(20 \mathrm{~Hz}, 10 \mathrm{~min})$ specimens were made as outlined in Materials and Methods. More samples were taken for "control" and "LTF" experiments, since the main goal was to detect long-lasting synaptic differences. The populations of synapses successfully sampled and measured under the four experimental conditions were compared to ascertain whether any overall differences could be detected. Since the physiological results showed that not all terminals are modified on a long-term basis in LTF experiments, it was expected that long-lasting ultrastructural changes would occur only in a minority of synapses.

Comparison of single sections of "control" and "LTF" samples showed no major differences in general ultrastructural features (Fig. 7 $A, B$ ). However, in "LTF" samples, examples of synapses with multiple dense bodies were more easily found than in "control" samples. A rare example of a synapse from an "LTF" sample sectioned in face view at the end of a terminal is shown in Figure 7, $C$ and $D$. In this example, four closely spaced dense bodies are apparent. Excitatory synapses with this number of dense bodies were almost never seen in "control" or "stimulated" samples. Such observations suggested that one possible correlate of the long-lasting phase of LTF is the appearance of additional presynaptic dense bodies at some synapses.

In "short-term stimulated" $(20 \mathrm{~Hz}, 1 \mathrm{~min})$ and "long-term stimulated" (20 Hz, $10 \mathrm{~min})$ samples, some ultrastructural al-
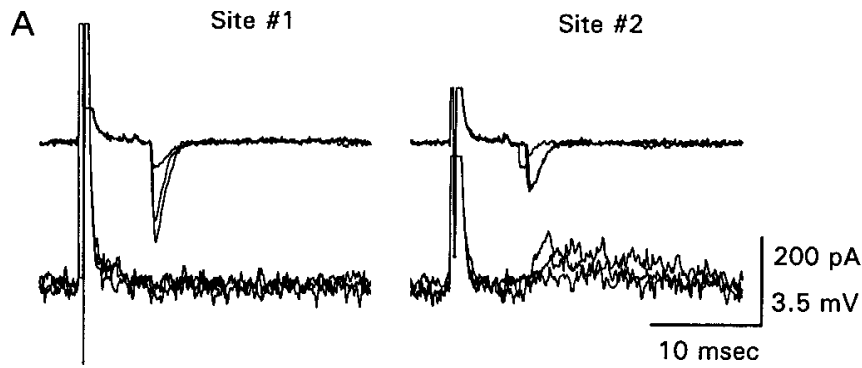

B
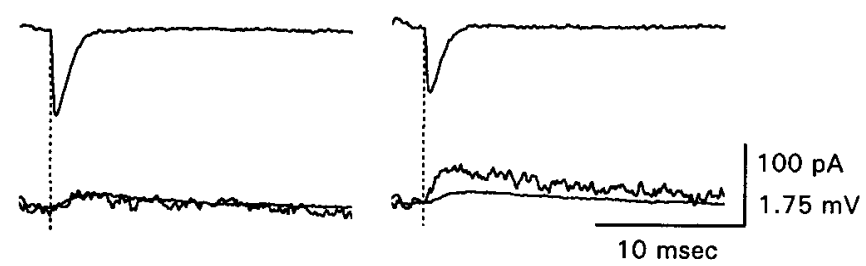

C
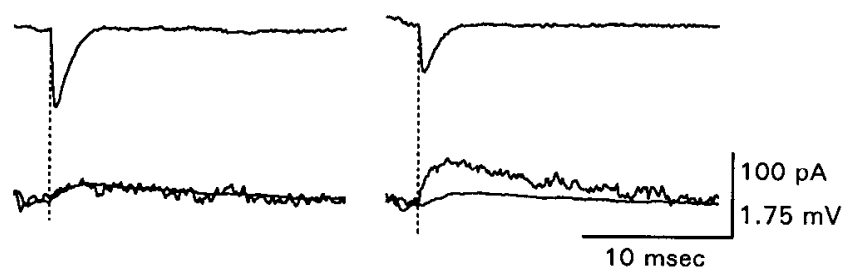

Figure 6. Variation in performance at individual terminals on a single muscle fiber before and after induction of LTF. Two macropatch recording sites show examples of "ineffective" and "effective" transmission of quanta at an active site on the muscle fiber. A:Site \#1 ("ineffective"), Quantal currents evoked at $1 \mathrm{~Hz}$ were typically not accompanied by a detectable evoked EPSP. This is shown by three representative, superimposed traces of simultaneous recordings at the macropatch site (upper trace) and at an intracellular site about $200 \mu \mathrm{m}$ distant (lower trace). Site \#2 ("effective"), Quantal release was similar to that of Site \#1, but at this location each quantum corresponded to a synchronous, intracellular EPSP. $B$, For each site, 13 quanta were synchronized and averaged (top traces). The intracellular traces were locked in time to the quantal recordings and averaged. The "noisy" average consists only of the 13 intracellular traces corresponding to the quantal currents shown. The "smooth" average includes all 500 responses analyzed at each site. Note that the two averaged traces are similar in amplitude at Site \#1 and that they do not coincide exactly with the quantal currents. At Site $\# 2$, there is a clear relationship of quantal currents to the EPSPs; the average of the 13 simultaneous events is substantially larger than the overall average of all 500 responses. The results suggest that at Site \#2, but not at Site \#1, quantal currents were effectively transmitted and contributed significantly to the overall intracellular response. $C$, As in $B$, but analyzed $40 \mathrm{~min}$ later, after induction of LTF by $5 \mathrm{~min}$ of 20 $\mathrm{Hz}$ stimulation. Although transmitter release was increased at Site \#1 (not shown), it remained completely ineffective in producing EPSPs. Site \#2 transmitted well, but did not facilitate and therefore did not contribute to enhanced transmission associated with LTF.

terations were noted in electron micrographs. Presynaptic dense bodies were often less prominent in appearance in $20 \mathrm{~Hz}, 1 \mathrm{~min}$ material (Fig. 8). Some terminals had prominent vacuoles. In $20 \mathrm{~Hz}, 10$ min material, the presynaptic dense bodies were generally similar in appearance to those in "control" and "LTF" samples. However, several unusual examples werc found in which two dense bodies were either attached or very close together (Fig. 8). This was-never seen in other material. Images of this type suggested the possibility of splitting or division of dense bodies into separate entities. 

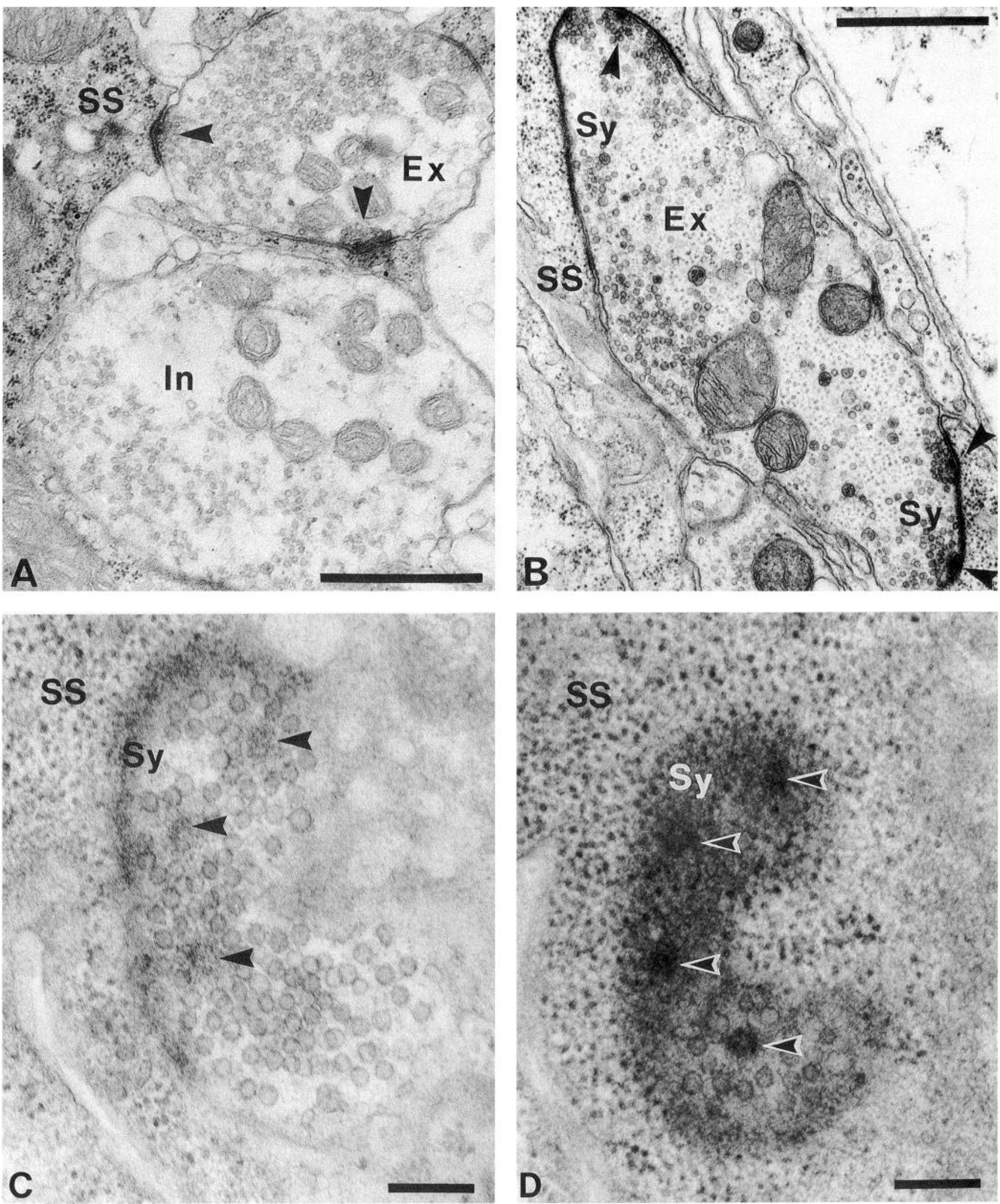

Figure 7. Electron micrographs of representative synapses in "control" and "long-term facilitated" opener muscle preparations. A, terminal from a "control" preparation; $B$, terminal from a "long-term facilitated" preparation; $C$ and $D$, four presynaptic dense bodies in a single synapse from a "long-term facilitated" terminal, shown in two successive sections at the same location. Ex, excitatory terminal; In, inhibitory terminal; arrowheads, presynaptic dense bodies; $S y$, synapses; $S S$, subsynaptic apparatus. Scale bars: $A$ and $B, 1 \mu \mathrm{m} ; C$ and $D, 0.2 \mu \mathrm{m}$. 

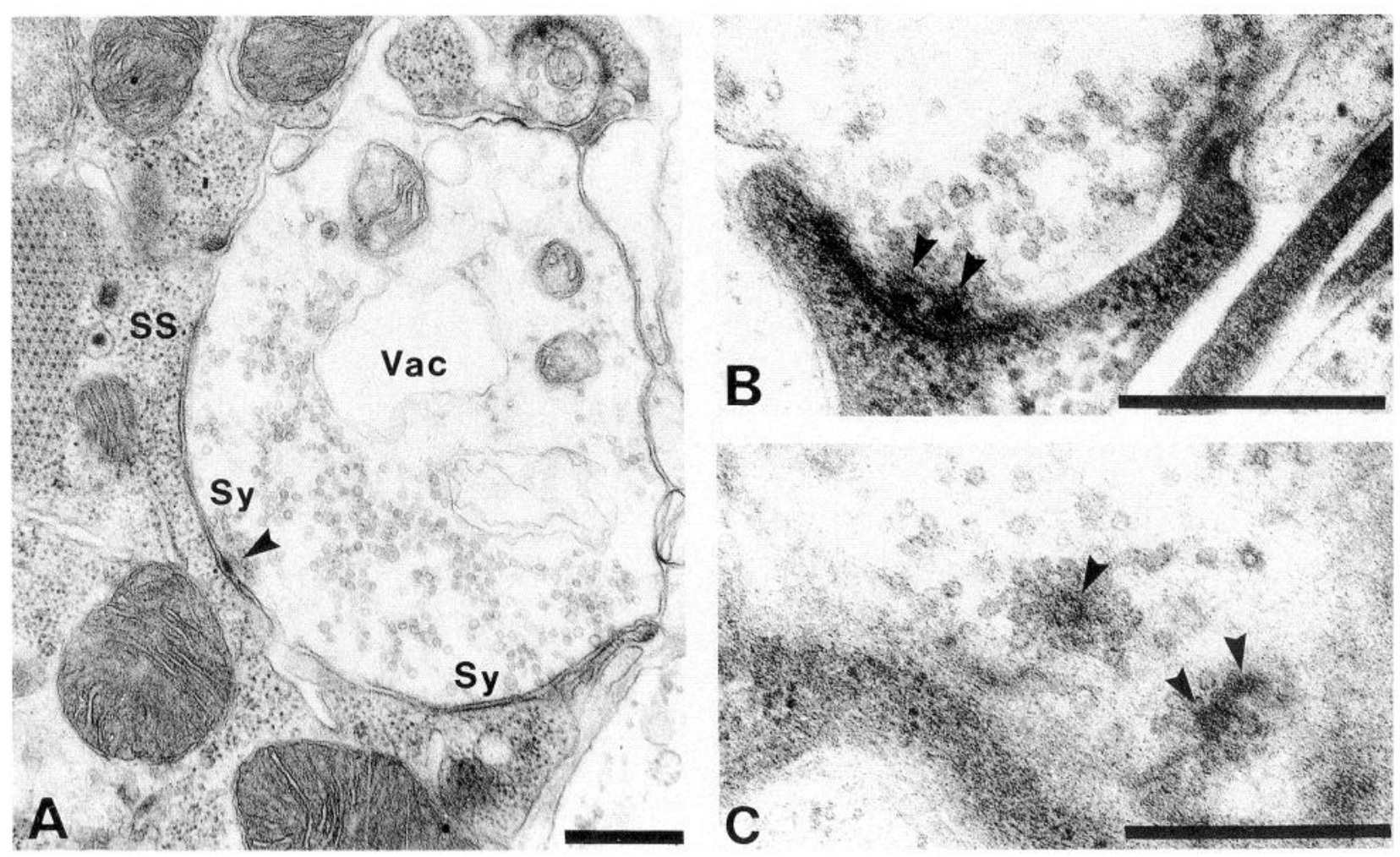

Figure 8. Electron micrographs of synapses in stimulated opener muscle preparations: brief and prolonged tetanic stimulation. $A$, Ending from a preparation subjected to approximately $1 \mathrm{~min}$ of stimulation at $20 \mathrm{~Hz}$ before activity was terminated by fixation. A presynaptic dense body is present (arrowhead), but it is less prominent than normally seen in "control" or "LTF" preparations. Vacuoles are seen in the central part of the nerve terminal. $B$, Synapse in "side view" from a preparation subjected to $20 \mathrm{~Hz}$ stimulation for approximately 10 min before fixation, illustrating a presynaptic dense body that appears to be splitting. $C$. Synapse in "face view" from the same preparation as in $B$, showing two presynaptic dense bodies in close proximity, one of which has a closely linked counterpart or satellite. Sy, synapse; $S S$, subsynaptic apparatus; Vac, vacuoles in stimulated nerve ending; arrowheads, presynaptic dense bodies. Scale bars, $0.5 \mu \mathrm{m}$.

Quantitative analysis of the serial sections provided information on synapse size and number, proportion of terminal surface area devoted to synapses, size of individual presynaptic dense bodies, and the number of dense bodies per unit of terminal surface area and per unit of synapse area (Table 2). Initial comparisons were made of the populations of synapses collected for the four experimental conditions.

Nerve terminals and synapses of "control" and "LTF" samples did not differ in synapse number, synapse contact area, synapse area per unit length of the terminal surface, or dense body size. Thus, some of the possibilities for activity-dependent long-lasting synaptic modification can be ruled out: synapses do not change in size or number, and individual presynaptic dense bodies do not change in size. The number of presynaptic dense bodies normalized for terminal surface area, or for synaptic contact area, was higher for LTF samples, but statistically the difference was not significant.

In samples subjected to $20 \mathrm{~Hz}$ stimulation, there were significant differences in synaptic size (for both short-term and long-term stimulation) and in synaptic and dense body number (for long-term stimulation). The data suggest that presynaptic dense bodies and synapses may alter in number during longterm stimulation. However, since these data were obtained from only one experiment, the observed differences are tentative and require further testing.

Since occurrence of perforated synapses has been reported to change in experimental studies of the mammalian brain (Gein- isman et al., 1986, 1989), we determined the percentages of perforated synapses in our sectioned material (Table 3 ). Perforated synapses were identified from serial reconstruction (see Fig. $1 B$ ). The overall percentage of perforated synapses was not different in "control" and "LTF" samples, but there was a difference in their distribution among the groups of synapses with different numbers of dense bars. In all samples but the "controls," perforated synapses were more common among synapses with higher numbers of dense bodies, but the relationships did not attain statistical significance. Altogether, the evidence for perforated synapses being a long-lasting manifestation of increased activity is not strong. It is possible that transient changes in synapse shape may result from stimulation, since the overall percentage of perforated synapses is somewhat higher in $20 \mathrm{~Hz}$, 10 min samples, but the effect, if present, is not robust enough to be unambiguous.

Counts were made of synaptic vesicles in the terminal as a whole and within $0.05 \mu \mathrm{m}$ of a synaptic membrane ("readily releasable vesicles," or RRV; Table 4). No significant differences between Control and LTF samples were detected. In short-term and long-term stimulated samples, RRVs were decreased. Thus, stimulation appears to decrease RRVs selectively, but there are no long-term alterations in RRVs or in the total vesicle population that could be demonstrated in LTF samples.

The populations of synapses with different numbers of dense bodies were compared to see whether they differed in the four experimental conditions, as suggested by some of the electron 


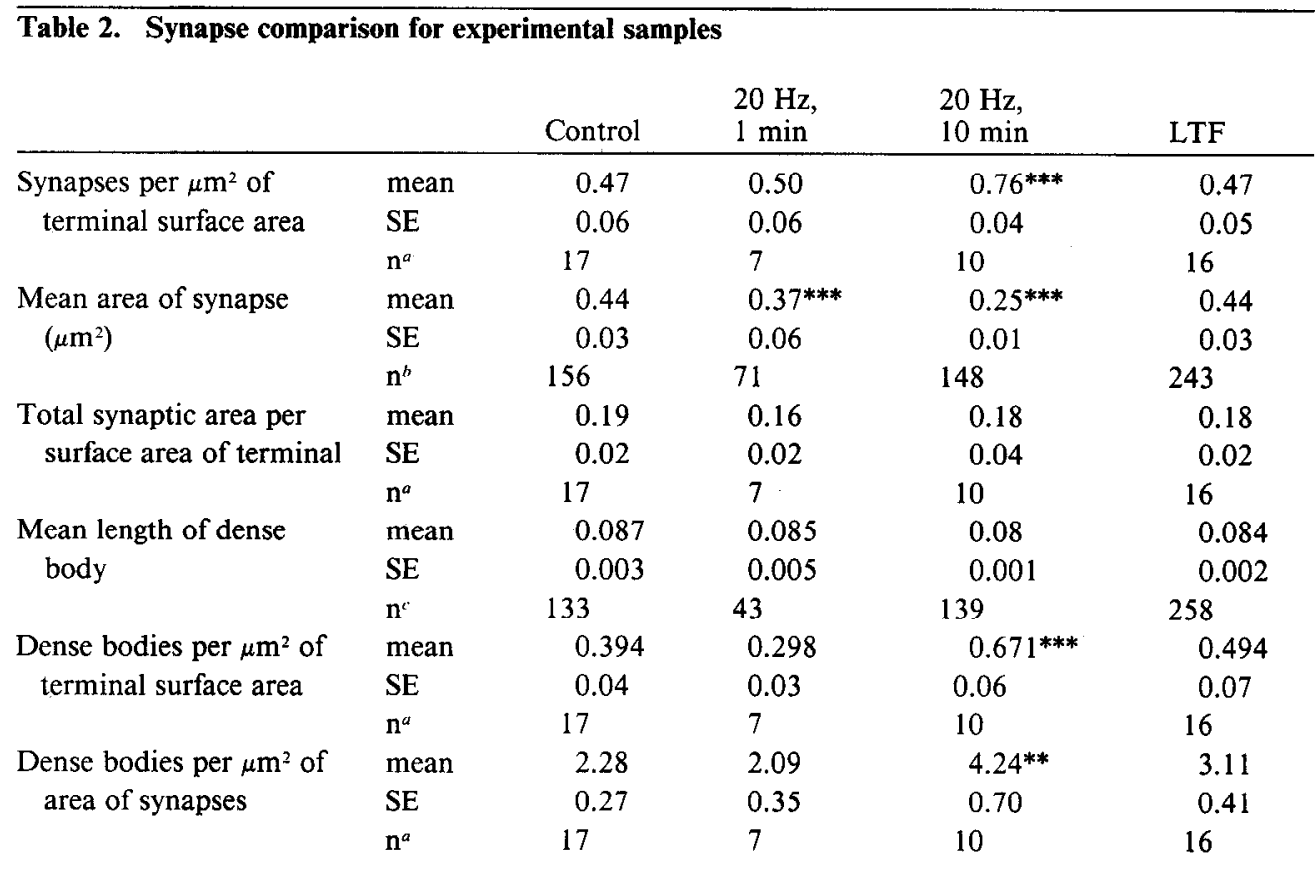

Statistical significance between the control group and each of the experimental groups was assessed with a two-tailed test or, if the distribution of data did not conform to the normal distribution, with a Mann-Whitney test.

*** $\mathrm{p}<0.01$.

*** $\mathrm{p}<0.001$

$\mathbf{n}=$ number of terminals.

${ }^{h} \mathbf{n}$ - number of synapses.

" $\mathbf{n}=$ number of dense bodies.

micrographs (Fig. 7). A histogram of the contact areas of synapses with different numbers of dense bodies (Fig. 9) confirms the pattern seen in Figure 3: synapses with multiple dense bodies tend to be larger than those with zero or one, particularly in Control and LTF samples. The relationship between synapse size and number of dense bodies was approximately linear. Some anomalies appear in the stimulated samples. In short-term stimulated material, there were no synapses with three or four dense bodies, and a few synapses with two dense bodies that were particularly large. In long-term stimulated material, the size relationship was not significant, and all synapses were smaller than in the other samples. These deviations from the normal pattern may reflect, in part, changes during stimulation, but

Table 3. Perforated synapses as percentage of total synapses

\begin{tabular}{llcll}
$\begin{array}{l}\text { Dense bodies } \\
\text { per synapse }\end{array}$ & Control & $\begin{array}{l}20 \mathrm{~Hz}, \\
1 \mathrm{~min}\end{array}$ & $\begin{array}{l}20 \mathrm{~Hz}, \\
10 \mathrm{~min}\end{array}$ & LTF \\
\hline 0 & $27 \%(51)$ & $7 \%(30)$ & $30 \%(46)$ & $12 \%(73)$ \\
1 & $34 \%(79)$ & $23 \%(40)$ & $41 \%(68)$ & $25 \%(104)$ \\
2 & $21 \%(24)$ & $100 \%(2)$ & $76 \%(29)$ & $43 \%(49)$ \\
3 & $33 \%(3)$ & - & - & $50 \%(12)$ \\
4 & - & - & - & $40 \%(5)$ \\
All synapses & $30 \%(157)$ & $18 \%(72)$ & $45 \%(143)$ & $26 \%(243)$
\end{tabular}

Sample sizes are shown in parentheses. Distributions of dense bodies in $20 \mathrm{~Hz}$, 1 min and LTF groups are significantly different from that of the "Control" group ( $\chi^{2}$ test, $p<0.001$ in both cases). The difference between the $20 \mathrm{~Hz}, 10 \mathrm{~min}$ group and the control group was not significant $(p>0.6)$. Relationships between the number of presynaptic dense bodies and the percentage of perforated synapses were not statistically significant, as judged by linear regression (control: $r=0.11$, $\mathrm{p}=0.89 ; 20 \mathrm{~Hz}, 1 \mathrm{~min}: \mathrm{r}=0.93, \mathrm{p}=0.23 ; 20 \mathrm{~Hz}, 10 \mathrm{~min}: \mathrm{r}=0.96, \mathrm{p}=0.19$; LTF: $r=0.84, p=0.08$ ). additional experiments would be required to establish this with more certainty. As far as long-lasting changes are concerned, LTF and control samples show the same pattern, but there were no synapses with four dense bodies in the control samples.

A further analysis of synapses with different numbers of dense bodies showed an increase in synapses with multiple dense bodies in the LTF samples (Fig. 10). However, since the majority of synapses are in the categories with zero and one dense bodies,

Table 4. Synaptic vesicles in sampled nerve endings and at synapses

\begin{tabular}{clrrrr} 
& & $\begin{array}{c}\text { Con- } \\
\text { trol }\end{array}$ & $\begin{array}{c}20 \mathrm{~Hz}, \\
1 \mathrm{~min}\end{array}$ & $\begin{array}{c}20 \mathrm{~Hz}, \\
10 \mathrm{~min}\end{array}$ & LTF \\
\hline Vesicles per $\mu \mathrm{m}^{3}$ of & mean & 815 & 524 & 909 & 757 \\
volume of terminal & $\mathrm{SE}$ & 121 & 108 & 165 & 53 \\
& $\mathrm{n}$ & 17 & 7 & 10 & 16 \\
Vesicles per synapse & mean & 605 & $382^{*}$ & 435 & 731 \\
& $\mathrm{SE}$ & 71 & 102 & 43 & 76 \\
& $\mathrm{n}$ & 17 & 7 & 10 & 16 \\
RRVs per synapse & mean & 41 & $24^{*}$ & $13^{* * *}$ & 38 \\
& $\mathrm{SE}$ & 3 & 6 & 1 & 5 \\
RRVs per $\mu \mathrm{m}^{2}$ of area of & $\mathrm{n}$ & 17 & 7 & 10 & 16 \\
synapse $($ density) & $\mathrm{SE}$ & 103 & $63^{* *}$ & $58^{* * *}$ & 95 \\
& $\mathrm{n}$ & 17 & 7 & 6 & 8 \\
& & 7 & 10 & 16
\end{tabular}

Statistical significance between the control group and each of the experimental groups was assessed with a two-tailed $t$ test or, if the distribution of data did not conform to the normal distribution, with a Mann-Whitney test. RRV, "Readily releasable" vesicles within $0.05 \mu \mathrm{m}$ of synapses. $\mathrm{n}$, number of terminals.

$* \mathrm{p}<0.05$.

$* * \mathrm{p}<0.01$.

$* * * \mathrm{p}<0.001$ 


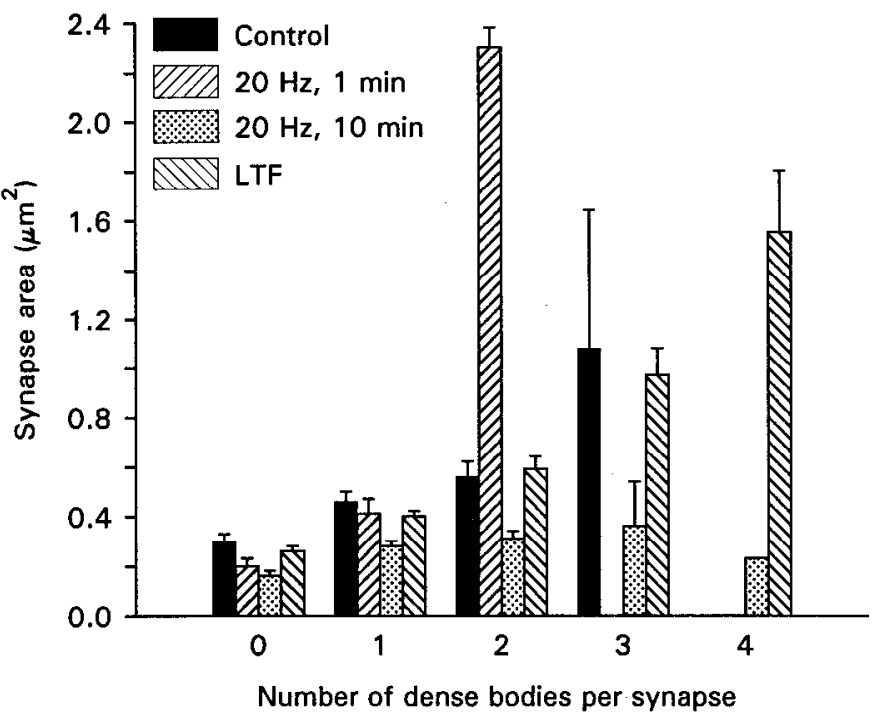

Figure 9. Relationship between synaptic contact area and dense bar number. The contact area of the synapse increases with the number of presynaptic dense bars (as shown also in Fig. $3 B$ ) for all samples. Synapses with three and four presynaptic dense bars were not found in 20 $\mathrm{Hz}, 1 \mathrm{~min}$ samples, and the few synapses with two presynaptic dense bars were particularly large. The relationship between the number of dense bodies and synaptic area was approximately linear, as judged by linear regression, for Control $(\mathrm{r}=0.93, \mathrm{p}=0.06)$ and $\operatorname{LTF}(\mathrm{r}=0.96$, $\mathrm{p}=0.01)$ data sets. In the $20 \mathrm{~Hz}, 1 \min (\mathrm{r}=0.90, \mathrm{p}=0.27)$ and 20 $\mathrm{Hz}, 10 \mathrm{~min}(\mathrm{r}=0.45, \mathrm{p}=0.44)$ data sets, there was not a significant detectable relationship between the two variables.

where the difference between control and LTF samples is less, no statistical difference between the distributions was obtained with a $\chi^{2}$ test. Figure 10 shows also the apparent reduction of synapses with multiple dense bodies in the short-term stimulation experiments.

A final test of the possible difference between control and LTF samples was conducted by counting the numbers of synapses with zero, one, or multiple dense bodies per unit surface area of the terminal (Fig. 11). In this comparison, there was a statistically significant increase in synapses with multiple dense bars in LTF samples. Synapses with zero and one dense bars wcre reduccd, but not significantly, in LTF samples. The data suggest that a few synapses are shifted into the multiple dense bar category as a result of stimulation leading to LTF.

\section{Discussion}

The present study utilized a simplified preparation to address several restricted questions on synaptic plasticity. These included the following: (1) What synaptic mechanisms are responsible for short-term facilitation? (2) Can synaptic correlates of long-term facilitation be observed with ultrastructural techniques? The experimental procedures used to address these questions - quantal analysis and serial sectioning for correlated ultrastructural studies-provide a framework for further analysis, but are not in themselves sufficient to provide answers to some of the possible mechanisms.

The isolated neuromuscular preparation of the crayfish provides a much more simplified experimental situation than the mammalian brain or invertebrate ganglionic preparations, because it restricts the type of mechanism that can operate: the neuronal cell body is absent, and interaction with other neurons and with neurohormones is minimal. Accordingly, the mech-

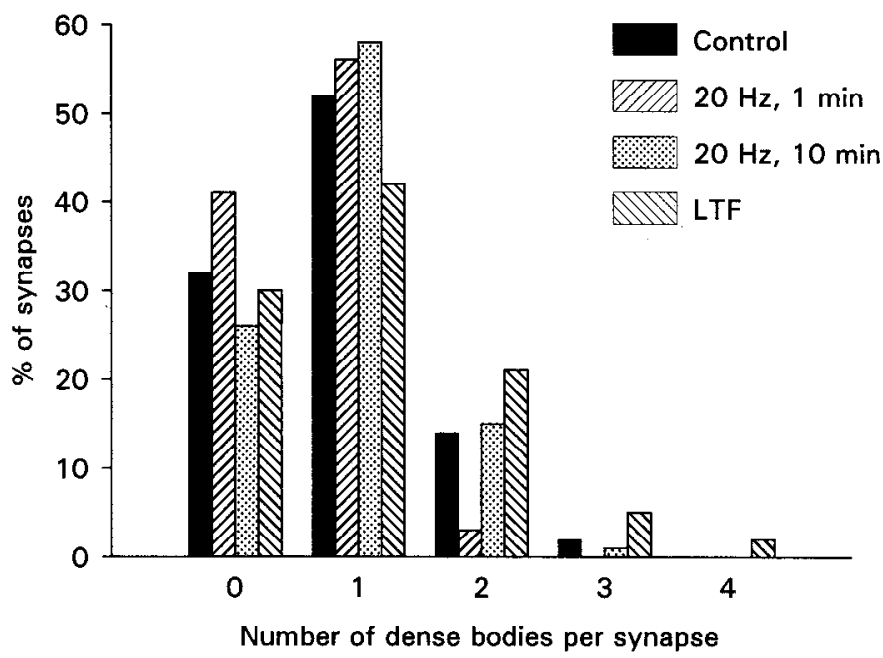

Figure 10. Distribution of presynaptic dense bars among synapses for Control, "long-term facilitated" $(L T F)$, and "stimulated" $(20 \mathrm{~Hz}, 1 \mathrm{~min}$ and $20 \mathrm{~Hz}, 10 \mathrm{~min}$ ) preparations. Synapses with multiple dense bodies (two or more) are better represented in $L T F$ terminals, and not prominent in $20 \mathrm{~Hz}, 1 \mathrm{~min}$ preparations. For statistical testing, the distributions of the three experimental groups were compared with the Control group, using a $\chi^{2}$ test. Only the $20 \mathrm{~Hz}, 1$ min data set differed significantly from Control ( $\mathrm{p}<0.006,2$ degrees of freedom).

anisms of plasticity that can operate are those within the nerve terminal itself, and possibly some that come into play as a result of interactions between the nerve terminal and its target (muscle) cells, or adjacent glial cells. Since long-lasting enhancement of transmission occurs even when neurotransmitter release is sup-

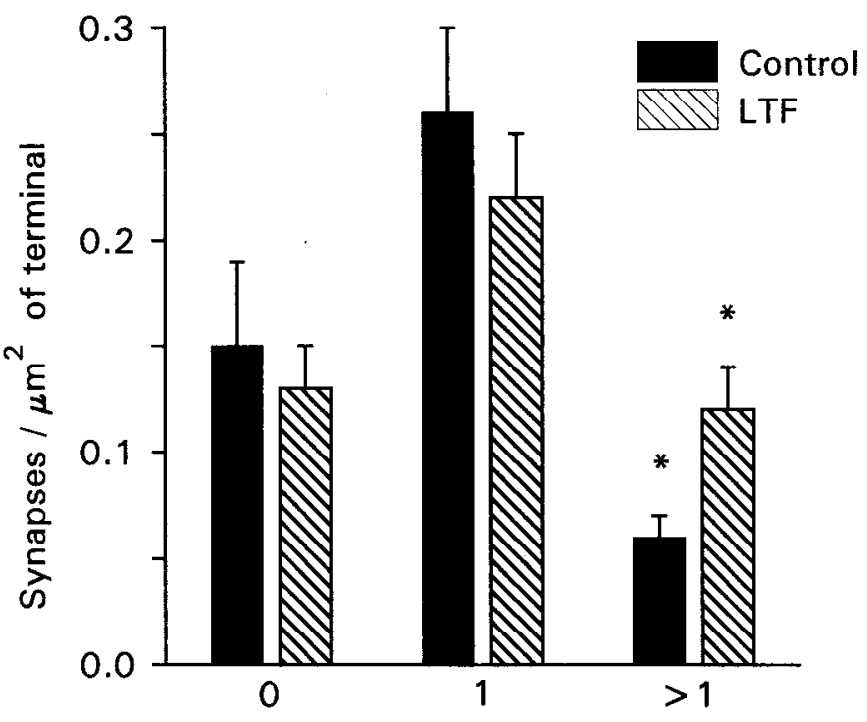

Number of dense bodies per synapse

Figure 11. Synapses with zero, one, or multiple presynaptic dense bodies per unit surface area of terminal in Control and $L T F$ samples. The overall total number of synapses per terminal surface area is the same in Control and $L T F$ samples $\left(0.47\right.$ synapses per $\mu \mathrm{m}^{2}$ terminal surface area). Collected results for sectioned terminals (series) from the terminals examined are presented. The concentration of synapses with multiple dense bodies is higher in the $L T F$ samples than in Control samples; the difference between the two groups (asterisks) was statistically significant $(t$ test, two tailed, $\mathrm{p}<0.05$ ). Synapses with no dense bars or single dense bars are lower in concentration for $L T F$ terminals, but the differences are not statistically significant. Error bars show SEM. 
pressed (Wojtowicz and Atwood, 1988), it is likely that intraterminal mechanisms are the most important. The changes that were investigated in this study are most likely homosynaptic, and involve those brought about by altered impulse activity in a single neuron. This provides information that can be used to assess the degree to which nerve activity per se is important in generating observable structural changes in more complex situations.

\section{Short-term facilitation}

Application of the nonuniform binomial model (Smith et al., 1991; Wojtowicz et al., 1991) to synaptic currents collected at different frequencies of stimulation at an active site showed that both $n$ and $\bar{p}$ increased with frequency (Table 1, Fig. 4). This general result is consistent with data from some previous investigations (Wernig, 1972; Hatt and Smith, 1976). The most reasonable interpretation is that the probability of release at transmitting synapses rises as a consequence of a higher background of intraterminal calcium (Zucker and Lara-Estrella, 1983; Delaney et al., 1989; Zucker et al., 1991), and as a result of calcium-mediated "priming" of presently poorly understood steps in the release process (Zigmond et al., 1974; Augustine et al., 1991; Bain and Quastel, 1992; Quastel et al., 1992). This process was not addressed in the present study. The small values for $n$, consistent with previous studies, are taken to indicate that only a few synapses on a terminal "bouton" are active at frequencies of stimulation of $1-10 \mathrm{~Hz}$. This interpretation is similar to that originally advanced by Zucker (1973) for the crayfish opener muscle preparation. The increase in $n$ with frequency suggests recruitment of synapses into the active pool, implying that there is a reservoir of inactive synapses from which recruitment can occur.

Results from a reconstructed active site showed that the number of "complex" synapses (i.e., those with multiple presynaptic dense bodics) was gencrally similar to the valucs of $n$ obtaincd at frequencies of $1-10 \mathrm{~Hz}$. At 3 and $4 \mathrm{~Hz}, n$ is 2 or 3 ; in the reconstruction, there are two large synapses that possess three dense bodies. At 5 and $10 \mathrm{~Hz}, n$ increases to 6 or 7 , and at 20 $\mathrm{Hz}$, to 10; the number of synapses with two and three dense bodies in the reconstruction is 10 . Thus, the inference is made that synapses most likely to release quanta at low frequencies of stimulation are those with multiple or unusually large dense bodies. Such synapses constitute a relatively small fraction of the total available "pool" at an active site. Among the available synapses, those without dense bodies are predicted to be inactive, those with one dense body inactive at low frequencies but potentially recruitable at higher frequencies when transmitter release is greatly facilitated, and those with two, three, or four dense bodies recruitable at relatively low frequencies of stimulation. The hypothesis that the more complex synapses are the ones that respond preferentially at low frequencies of stimulation is supported by these correlative observations.

Other evidence from electron micrographs supports the idea that the "complex" synapses are more active at low to moderate frequencies of stimulation. In the short-term stimulation experiment, fewer "complex" synapses were found, indicating a possible structural effect dependent upon synaptic activity. In long-term stimulation and LTF experiments, structural alterations were more likely to be found in "complex" synapses. Also, in other studies (Govind et al., 1994) "high-output" terminals differ from "low-output" terminals of the crayfish opener muscle mainly in possessing a higher proportion of "complex" synapses.
This is also true in other crustacean nerve terminals that have been studied (Govind and Meiss, 1979; Atwood and Marin, 1983). From these diverse observations, the picture emerges that low-frequency transmission is mainly handled by "complex" synapses, and high-frequency transmission involves progressive recruitment of the less complex synapses, of which there are many on each terminal.

The discovery of the "missing" quanta permits partial explanation of the apparent discrepancy between the quantal release parameters derived from extracellular, macropatch recordings and intracellular recordings (see Figs. 4, 5). It became apparent that many of the release sites detected by macropatch recordings are ineffective in producing EPSPs and do not contribute significantly to postsynaptic depolarization. The derived, average probability of the transmitting units is an order of magnitude higher in intracellular records than in macropatch records. We note that the derived probabilities are averages of individual probabilities at different synapses. The individual probabilities may vary by a factor of 10 (Smith et al., 1991; Wojtowicz et al., 1991). Therefore, we hypothesize that the synapses seen in intracellular records have, on average, higher probability of release. There are other complicating factors, such as nonlinear summation of quantal EPSPs and lower signal-to-noise ratio, which make the analysis of intracellular potentials a less reliable measure of transmitter release than the direct current recordings at release sites. The exact cause of the "missing" quanta remains unknown, although a previously advanced hypothesis, based on the signal attenuation by the subsynaptic network (Fig. 2) in the muscle fibers, is still being investigated by mathematical modeling techniques to determine its plausibility (Wojtowicz et al., 1989b). The higher estimated probability values for intracellular records may reflect the contribution of synapses located close to the muscle fiber on the subsynaptic apparatus.

\section{Iong-lasting synaptic changes}

Physiological analysis of active terminals that had been subjected to tetanic stimulation provided evidence for an increase in the number of synapses responding at low frequencies of stimulation. Application of quantal analysis showed that, following maintained stimulation, $n$ is observed to increase, but $\bar{p}$ changes little. This result is in accord with previous observations on intracellular records from small muscle fibers (Wojtowicz and Atwood, 1986) and extracellular records of synaptic currents from individual active sites (Wojtowicz et al., 1988, 1991). A hypothesis to account for this result is that a few synapses from among those sampled undergo permanent or semipermanent recruitment into the active pool. This implies that there are structural or chemical changes at some synapses that make them active at low frequencies, while others remain unmodified (or less modified) and inactive. From the results on short-term facilitation, the hypothesis can be cxtended to include the concept that the appearance of additional physiologically active synapses should have a morphological counterpart in the appearance of additional "complex" synapses in terminals expressing the longlasting phase of LTF.

The physiological results suggested that the number of additional active synapses is small. Extensive ultrastructural sampling of "LTF" terminals revealed a significant but small increase in the number of "complex" synapses (Fig. 11). Other possibilities for synaptic modification, including increased readily releasable synaptic vesicles, increase in perforated synapses, change in size of synapses, and change in size of presynaptic 
dense bodies, were all negative or nonsignificant when "control" and "LTF" samples were compared. Thus, the major point of difference between LTF and "control" terminals is the somewhat greater spatial density of synapses with multiple dense bodies in the former. This result is in accord with an earlier study by Chiang and Govind (1986) on lobster neuromuscular junctions facilitated by exposure to ouabain.

That new presynaptic dense bodies can be evolved from existing ones is suggested by a few examples of "splitting" dense bodies in terminals stimulated at $20 \mathrm{IIz}$ for $10 \mathrm{~min}$ (Fig. 8). It also appears possible that dense bodies may change their appearance and become less prominent during certain stages of stimulation. In $20 \mathrm{~Hz}, 1 \mathrm{~min}$ samples, there were fewer visible dense bodies and, significantly, very few synapses with multiple dense bodies (in fact, none with three or four dense bodies). Although the sample was small, the few synapses with two dense bodies were larger than in "control" and "LTF" samples. Such an effect could result from apparent loss of one or two dense bodies from synapses initially possessing three or four of these structures, since such synapses tend to be larger than others. There was no apparent difference in size of synapses having zero or one dense body. Taken together, these observations are an indication of activity-dependent changes involving initial loss of readily releasable vesicles and subtraction of material from dense bodies at active synapses. There appears to be a selective effect on large synapses with multiple dense bodies. All of these observations suggest greater malleability of "complex" synapses during stimulation.

The general hypothesis for activity-dependent changes that emerges from the current observations is that synapses can be either temporarily or permanently recruited from an inactive state to an active state. Initially, a few synapses of the many available have a relatively high probability of response. We identify these provisionally as the "complex" synapses possessing multiple dense bodies. These synapses are postulated to be effective during low frequencies of stimulation. Short-term stimulation at higher frequencies leads to increased probability of release for the synapses already "primed," and recruits additional synapses to the active pool. If the stimulation is maintained, semipermanent structural alterations are induced, leading to a modest increase in the number of synapses capable of releasing transmitter at low frequencies of stimulation. The structural change detected in the present study is the splitting of preexisting dense bodies to endow a few synapses with more dense bodies than they initially had. This correlates with longlasting enhancement of transmission at low frequencies of stimulation (the long-lasting phase of LTF).

The occurrence of more, or larger, presynaptic dense bodies or active zones at a synapse is thought to increase the probability of release at that synapse by virtue of the higher numbers of clustered calcium channels. This possibility has been particularly well explored at the frog neuromuscular junction (Propst et al., 1986; Propst and Ko, 1987; Kashapova et al., 1991). In crayfish and other crustacean synapses, this principle may also apply (Pearce et al., 1986; Govind and Walrond, 1989). Whether the establishment of new dense bodies in a synapse, suggested in the present study, leads to redistribution of existing presynaptic calcium channels or to activation or insertion of new ones remains to be determined. Since LTF is induced in isolated distal axons, de novo protein synthesis is ruled out as a mechanism. In addition, LTF has been found to occur in synthesisblocking concentrations of cycloheximide (P. Nguyen and $M$.
Wojtowicz, unpublished observations). Thus, the nerve ending must create new active synapses with materials already available locally.

The mechanism for local splitting of presynaptic dense bodies also remains to be clarified. It is known that the long-lasting phase of LTF requires the participation of cAMP-activated protein kinase (Dixon and Atwood, 1989), which could in turn act on a number of substrate proteins, including cytoskeletal elements known to be involved in cell shape changes in some systems. In addition, present evidence suggests the interaction of a complex of synaptic vesicle proteins at the active zone (Bennett and Scheller, 1993; Greengard et al., 1993). Several of these proteins are targets for phosphorylation and dephosphorylation, and their aggregation and interaction at the active zone may be influenced by availability of cAMP and its dependent kinases. Thus, the appearance and integrity of presynaptic dense bodies may have a complex regulation, dependent upon several proteins and second messengers.

In conclusion, the general hypothesis of concurrent physiological and ultrastructural synaptic modification by activity per se is supported by these observations on an identified neuron subjected to known changes in activity. The concept of "silent" and "active" synapses, and their possible interconversion, is also supported. These concepts are possibly applicable to the synapses of the mammalian CNS (Lisman and Harris, 1993), where structural changes of a similar nature have been noted and for which it has been suggested that the number of functional synaptic sites can be altered. However, the changes in the mammalian CNS involve more complex interactions, and involve more than homosynaptic plasticity.

\section{References}

Abrams TW, Kandel ER (1988) Is contiguity detection in classical conditioning a system or a cellular property? Learning in Aplysia suggests a possible molecular site. Trends Neurosci 11:128-135.

Artyukhina NI, Ryabinina MA (1978) Ultrastructural changes in synapses of the rabbit sensomotor cortex during stimulation of the reticular formation. Zh Vyssh Nerv Deyat 28:1222-1230.

Atwood HL, Kwan I (1976) Synaptic development in the crayfish opener muscle. J Neurobiol 7:289-312.

Atwood HL, Marin L (1983) Ultrastructure of synapses with different transmitter-releasing characteristics on motor axon terminals of a crab, Hyas areneas. Cell Tissue Res 231:103-115.

Atwood HL, Wojtowicz JM (1986) Short-term and long-term plasticity and physiological differentiation of crustacean motor synapses. Int Rev Neurobiol 28:275-362.

Atwood HL, Swenarchuk LE, Gruenwald CR (1975) Long-term synaptic facilitation during sodium accumulation in nerve terminals. Brain Res 100:198-204.

Atwood HL, Parnas H, Parnas I, Wojtowicz JM (1987) Quantal currents cvoked by graded intracellular depolarizations of crayfish motor terminals. J Physiol (Lond) 383:587-599.

Atwood HL, Dixon D, Wojtowicz JM (1989) Rapid introduction of long-lasting synaptic changes at crustacean neuromuscular junctions. J Neurobiol 20:373-385.

Augustine GJ, Adler EM, Charlton MP (1991) The calcium signal for transmitter secretion from presynaptic nerve terminals. Ann NY Acad Sci 635:365-381.

Bailey CH, Chen M (1983) Morphological basis of long-term habituation and sensitization in Aplysia. Science 220:91-93.

Bailey CH, Kandel ER (1993) Structural changes accompanying memory storage. Annu Rev Physiol 55:397-426.

Bailey CH, Montarolo P, Chen M, Kandel ER, Schacher S (1992) Inhibitors of protein and RNA synthesis block structural changes that accompany long-term heterosynaptic plasticity in Aplysia. Neuron 9:749-758.

Bain AI, Quastel DMJ (1992) Multiplicative and additive $\mathrm{Ca}^{2+}$-de- 
pendent components of facilitation at mouse endplates. $J$ Physiol (Lond) 455:383-405.

Bennett MK, Scheller RH (1993) The molecular machinery for secretion is conserved from yeast to neurons. Proc Natl Acad Sci USA 90: 2559.

Bittner GD (1968) The differentiation of crayfish muscle fibers during development. J Exp Zool 167:439 456.

Black JE, Isaacs KR, Anderson BJ, Alcantara AA, Greenough WT (1990) Learning causes synaptogenesis, whereas motor activity causes angiogenesis, in cerebellar cortex of adult rats. Proc Natl Acad Sci USA $87: 5568-5572$.

Byrne JH, Zwartjes R, Homayouni R, Critz SD, Eskin A (1993) Roles of second messenger pathways in neuronal plasticity and in learning and memory. Insights gained from Aplysia. In: Advances in second messenger and phosphoprotein research, Vol 27 (Shenolikar S, Nairn AC, eds), pp 47-108. New York: Raven.

Chiang RG, Govind CK (1986) Reorganization of synaptic ultrastructure at facilitated lobster neuromuscular terminals. J Neurocytol 15 63-74.

Delaney KR, Zucker RS, Tank DW (1989) Calcium in motor nerve terminals associated with posttetanic potentiation. J Neurosci 9:35583567.

Dixon D, Atwood HL (1989) Adenylate cyclase system is essential for long-term facilitation at the crayfish neuromuscular junction. J Neurosci 9:4246-4252

Florey E, Cahill MA (1982) The innervation pattern of crustacean skeletal muscle. Cell Tissue Res 224:527-541.

Geinisman Y, de Toledo-Morrell L, Morrell F (1986) Loss of perforated synapses in the dentate gyrus: morphological substratc of $\mathrm{mcm}$ ory deficit in aged rats. Proc Natl Acad Sci USA 83:3027-3031.

Geinisman Y, Morrell F, de Toledo-Morrell L (1989) Perforated synapses on double-headed dendritic spines: a possible structural substrate of synaptic plasticity. Brain Res 480:326-329.

Geinisman Y, Morell F, de Toledo-Morell L (1992) Increase in the number of axospinous synapses with segmented postsynaptic densities following hippocampal kindling. Brain Res 569:341-347.

Gomez RA, Pozzo M, Aoki A, Ramirez OA (1990) Long-term potentiation-induced synaptic changes in hippocampal dentate gyrus of rats with an inborn low or high learning capacity. Brain Res 537:293297.

Govind CK, Meiss DE (1979) Quantitative comparison of low- and high-output neuromuscular synapses from a motoneuron of the lobster (Homarus americanus). Cell Tissue Res 198:455-463.

Govind CK, Walrond JP (1989) Structural plasticity at crustacean neuromuscular synapses. J Neurobiol 20:409-421.

Govind CK, Meiss DE, Pearce J (1982) Differentiation of identifiable lobster neuromuscular synapses during development. J Neurocytol 11:235-247.

Govind C, Pearce J, Wojtowicz JM, Atwood HL (1994) "Strong" and "weak" synaptic differentiation in the crayfish opener muscle: structural correlates. Synapse 16:45-58.

Greengard P, Valtorta F, Czernik AJ, Benfanati F (1993) Synaptic vesicle phosphoproteins and regulation of synaptic function. Science 259:780-785.

Greenough WT (1984) Structural correlates of information storage in the mammalian brain: a review and hypothesis. Trends Neurosci 7:229-233.

Greenough WT, West RW, DeVoogd TJ (1978) Subsynaptic plate perforations: changes with age and experience in the rat. Science 202 1096-1098.

Greenough WT, Hwang HMF, Gorman C (1985) Evidence for active synapse formation or altered postsynaptic metabolism in visual cortex of rats reared in complex environments. Proc Natl Acad Sci USA 82: $4549-4552$

Haley JE, Wilcox GL, Chapman Pf (1992) The role of nitric oxide in hippocampal long-term potentiation. Neuron 8:211-216.

Hatt $\mathrm{H}$, Smith DO (1976) Non-uniform probabilities of quantal release at the crayfish neuromuscular junction. J Physiol (Lond) 259:395404.

Hawdon G, Rees S, Rawson JA (1988) Ultrastructure of synapses in the cerebellar cortex after long-term activation of climbing fibres. Neurosci Lett 91:7-13.

Jahromi SS, Atwood HL (1974) Three-dimensional ultrastructure of the crayfish neuromuscular apparatus. J Cell Biol 63:599-613.

Jones DG, Calverley RKS (1991) Perforated and non-perforated syn- apses in rat aneocortex: three-dimensional reconstructions. Brain Res $556: 247-258$

Kashapova LA, Moshkov DA, Bezgina EN (1991) Active zones and plasticity of motor nerve terminals. In: Plasticity of motoncuronal connections (Wernig A, ed), pp 163-173. Amsterdam: Elsevier.

Lee K, Oliver M, Schottler F, Creager R, Lynch G (1979) Ultrastructural effects of repetitive synaptic stimulation in the hippocampal slice preparation: a preliminary report. Exp Neurol 65:478-480.

Lisman JE, Harris KM (1993) Quantal analysis and synaptic anatomy-integrating two views of hippocampal plasticity. Trends Neurosci 16:141-147.

Lnenicka GA, Atwood HL (1985) Long-term facilitation and longterm adaptation at synapses of a crayfish phasic motoneuron. J Neurobiol 16:97-110.

McNaughton BL (1993) The mechanism of expression of long-term enhancement of hippocampal synapses: current issues and theoretical implications. Annu Rev Physiol 55:375-396.

Nazif FA, Byrne JH, Cleary LJ (1991) cAMP induces long-lerm morphological changes in sensory neurons of Aplysia. Brain Res 539:324327.

Pearce J, Govind C, Shivers RR (1986) Intramembranous organization of lobster excitatory neuromuscular synapses. J Neurocytol 15 : 241-252.

Petit TL, LeBoutillier JC, Markus EJ, Milgram NW (1989) Synaptic structural plasticity following repetitive activation in the rat hippocampus. Exp Neurol 105:72-79.

Petukhov VV, Popov VI (1986) Quantitative analysis of ultrastructural changes in synapses of the rat hippocampal field $C A 3$ in vitro in different functional statcs. Neuroscience 18:823-835.

Propst JW, Ko C-P (1987) Correlations between active zone ultrastructure and synaptic function studied with freeze-fracture of physiologically identified frog neuromuscular junctions. J Neurosci 7:36543664.

Propst JW, Herrera AA, Ko C-P (1986) A comparison of active zone structure in frog neuromuscular junctions from two fast muscles with different synaptic efficacy. J Neurocytol 15:525-534.

Quastel DMJ, Guan Y-Y, Saint DA (1992) The relation hetween transmitter release and $\mathrm{Ca}^{2+}$ entry at the mouse motor nerve terminal: role of stochastic factors causing heterogeneity. Neuroscience 51:657671.

Schuster T, Krug M, Wenzel J (1990) Spinules in axospinous synapses of the rat dentate gyrus: changes in density following long-term potentiation. Brain Res 523:171-174.

Sherman RG, Atwood HL (1971) Synaptic facilitation: long-term neuromuscular facilitation in crustaceans. Science 171:1248-1250.

Smith BR, Wojtowicz JM, Atwood HL (1991) Maximum likelihood estimation of non-uniform transmitter release probabilities at the crayfish neuromuscular junction. J Theor Biol 150:457-472.

Tsien RY (1989) Fluorescent probes of cell signaling. Annu Rev Neurosci $12: 227-253$.

Verma A, Hirsch DJ, Glatt CE, Ronnett GV, Snyder SH (1993) Carbon monoxide: a putative neural messenger. Science 259:381-384.

Wenzel J, Kammerer E, Kirsche W, Matties H, Wenzel M (1980) Elcctron microscopic and morphometric studies on synaptic plasticity in the hippocampus of the rat following conditioning. J Hirnforsch $21: 647-654$

Wernig A (1972) Changes in statistical parameters during facilitation at the crayfish neuromuscular junction. J Physiol (Lond) 226:751759.

Wojtowicz JM, Atwood HL (1984) Presynaptic membrane potential and transmitter release at the crayfish neuromuscular junction. J Neurophysiol 52:99-113.

Wojtowicz JM, Atwood HL (1985) Correlation of presynaptic and postsynaptic events during establishment of long term facilitation at the crayfish neuromuscular junction. J Neurophysiol 54:220-230.

Wojtowicz JM, Atwood HL (1986) Long-term facilitation alters transmitter releasing properties at the crayfish neuromuscular junction. $J$ Neurophysiol 55:484-498.

Wojtowicz JM, Atwood HL (1988) Presynaptic long-term facilitation at the crayfish neuromuscular junction: voltage-dependent and iondependent phases. J Neurosci 8:4667-4674.

Wojtowicz JM, Parnas I, Parnas H, Atwood HL (1988) Long-term facilitation of synaptic transmission demonstrated with macro-patch recording at the crayfish neuromuscular junction. Neurosci Lett 90 : 152-158. 
Wojtowicz JM, Marin L, Atwood HL (1989a) Synaptic restructuring during long-term facilitation at the crayfish neuromuscular junction. Can J Physiol Pharmacol 67:167-171.

Wojtowicz JM, Miller K, Winslow J, Atwood HL (1989b) A possible source of attenuation of quantal currents at the crayfish neuromuscular synapse. Soc Neurosci Abstr 15:257.

Wojtowicz JM, Smith BR, Atwood HL (1991) Activity-dependent recruitment of silent synapses. Ann NY Acad Sci 627:169-179.

Zigmond RE, Schon F, Iversen LL (1974) Increased tyrosine hydroxylase activity in the locus coeruleus of rat brain stem after reserpine treatment and cold stress. Brain Res 70:547-552.
Zucker RS (1973) Changes in the statistics of transmitter release during facilitation. J Physiol (Lond) 229:787-810.

Zucker RS (1989) Short-term synaptic plasticity. Annu Rev Neurosci $12: 13-31$.

Zucker RS, Lara-Estrella LO (1983) Post-tetanic decay of evoked and spontaneous transmitter release and a residual-calcium model of synaptic facilitation at crayfish neuromuscular junctions. J Gen Physiol 81:355-372.

Zucker RS, Delaney KR, Mulkey R, Tank DW (1991) Presynaptic calcium in transmitter release and posttetanic potentiation. Ann NY Acad Sci 635:191-207. 